Acta Crystallographica Section A

Foundations of Crystallography

ISSN 0108-7673

\section{Report of the Executive Committee for 2003}

\section{Meetings}

The IUCr sponsored the following meetings held during 2003:

International School on Crystal Growth of Technologically

Important Electronic Materials, Mysore, India, 20-27 January.

VI Latin American Workshop on Magnetism, Magnetic Materials and Their Applications, Chihuahua, Mexico, 7-11 April.

BCA/CCG Ninth Intensive Course in X-ray Structure Analysis,

Durham, UK, 7-14 April.

School on X-ray Charge Density and the $X D$ Programming

Package, Buffalo, New York, USA, 13-17 May.

Third National Crystal Chemical Conference, Chernogolovka, Russia, 19-23 May.

School on High Pressure Crystallography, Erice, Italy, 4-15 June. International School on Electron Crystallography, Moscow, Russia, 23-27 June.

Third European Charge Density Meeting, Aarhus, Denmark, 24-29 June.

ACA Annual Meeting, Covington, Kentucky, USA, 26-31 July.

ACA Summer Course in Small Molecule Crystallography, Indiana,

PA, USA, 3-13 August.

AsCA '03 and Crystal-23 Combined Conference, Broome,

Australia, 10-13 August.

Biological Structure Workshop, Broome, Australia, 13-15 August.

Sagamore XIV Meeting on Charge, Spin and Momentum Densi-

ties, Broome, Australia, 13-18 August.

Indaba 4 (satellite to ECM-21), Kruger National Park, South Africa, 17-22 August.

African Neutron Diffraction Meeting (satellite to ECM-21), Pelindaba, South Africa, 21-22 August.

21st European Crystallographic Meeting (ECM-21), Durban, South Africa, 24-29 August.

XIX Conference on Applied Crystallography, Kraków, Poland, 1-4 September.

Summer School on Polycrystalline Structure Determination by

Direct Methods, Kraków, Poland, 4-7 September.

International Conference on Aperiodic Crystals, Belo Horizonte,

Brazil, 8-13 September.

Conference on Structure Solution from Powder Data, Stara Lesna,

Czech Republic, 14-19 September.

XV International Conference on X-ray Analysis \& Crystal Chemistry of Minerals, St Petersburg, Russia, 15-19 September.

First Workshop on Radiation Based Analytical Techniques and 9th Symposium of International Radiation Physics Society, Cape Town, South Africa, 24-31 October.

IV National Conference on Application of X-ray, Synchrotron Radiation, Neutrons and Electrons for Material Characterization, Moscow, Russia, 17-23 November.

Workshop on High Pressure Structure and Reactivity: The Science of Change, Berkeley, California, USA, 4-7 December.
Anniversary Fedorov Session 2003, St Petersburg, Russia, 9-10 December.

International School on Crystal Growth, Characterization and Applications, La Pedrera, Rocha, Uruguay, 9-13 December.

The Executive Committee met in Broome, Australia, in August. The Finance Committee met once, in Copenhagen, Denmark, in March, to prepare its advice and recommendations on finances, establishment and staff matters. The most important items of business dealt with by the Executive Committee at its meeting, and in postal ballots, were:

editorial policy, pricing policy and subscription rates, approval of appointments of Co-editors, electronic publishing, archival policy, Special Issues, open access and other matters concerning the IUCr journals;

approval of the launch of Acta Crystallographica Section F; facility information pages for Journal of Synchrotron Radiation; review of contract with Blackwell Munksgaard;

approval of the audited accounts for the previous year;

General Fund estimates;

status of membership subscriptions;

investment policy;

funding and uses of the Publications and Journals Development

Fund and the Research and Education Fund;

revision of guidelines for the Sub-committee on the Union

Calendar;

Journal Grants Fund;

cooperation with databases, open-access databases;

progress with Volumes A, A1, B, C, D, E, F and G of International

Tables and development of associated software, consideration of possible new volumes;

IUCr Newsletter;

World Directory of Crystallographers;

promotional activities;

appointment of Ewald Prize Selection Committee;

discussion of the arrangements for the 2005 General Assembly and

Congress;

election procedures for members of Executive Committee.

Other items dealt with in this way were:

uses of the Crystallographic Information File (CIF), trademark applications, work of the Committee for the Maintenance of the CIF Standard (COMCIFS), provision of checking services to other publishers;

consideration of publications, jointly with Oxford University Press, in the IUCr/OUP Book Series;

crystallography in Africa;

relations with other Scientific Unions;

Inter-Union Bioinformatics Group;

review of the activities of the Commissions;

review of the activities of Regional Associates;

review of the reports of IUCr Representatives on other bodies. 
Items concerning the Chester office were:

staffing requirements, upgrading of office technology, provision of internet services.

\section{Publications}

Volume 59 of Acta Crystallographica Sections A, B, C, D and E, Volume 36 of Journal of Applied Crystallography, Volume 10 of Journal of Synchrotron Radiation and Volume D of International Tables for Crystallography were published.

\section{Adhering Bodies}

A list of Adhering Bodies of the Union, with names and addresses of the Secretaries of the National Committees for Crystallography, was published as Annex IV to the Report of the Nineteenth General Assembly and International Congress of Crystallography [Acta Cryst. (2003), A59, 374-433].

\section{Work of the Commissions}

\subsection{Commission on Journals}

4.1.1. Overview. The year saw the publication of a total of 10,715 pages and 2,899 articles compared with 9,078 pages and 2,369 articles in 2002; the distribution across the IUCr journal titles has been buoyant. Special Issues have been published, namely the CCP4 Study Weekend on Experimental Phasing in Acta Cryst. Section D, the XIIth International Conference on Small-Angle Scattering in $J A C$ and, in $J S R$, the XIV Russian Synchrotron Radiation Conference and a Special Issue on BioXAS and Structural Genomics. The citation impact of IUCr journals continued to be high, occupying three of the top five ranking positions. The overall publication times were Acta Cryst. Section A 4.5 months, Section B 5.4 months, Section C 2.2 months, Section D 4.9 months, Section E 0.9 months, JAC 7.3 months and JSR 8.2 months.

The overall withdrawal plus rejection rate for the journals was $20 \%$, very similar to recent years. In addition, highlighting of articles from our journals 'press-release style' has continued in the $\mathrm{IUCr}$ Newsletter. We gratefully acknowledge the cooperation of the Editor of the IUCr Newsletter (J. L. Flippen-Anderson) with that activity.

Finally, as ever, I have greatly appreciated the high professional interactions and knowledge of the IUCr Chester staff, notably P. R. Strickland (Managing Editor), B. McMahon (Research and Development Officer), A. J. Sharpe (Promotions Officer) and M. H. Dacombe (Executive Secretary), and indeed all the IUCr staff at Abbey Square, Chester, UK. I would also like to highlight the work by the Chester team leading to the introduction of on-line submission, which has proved popular with authors, editors and referees, considerably expediting the speed and ease of interaction even when travelling! In consultation with relevant editors, the Journals Working Group has continued with the design and distribution of publicity leaflets for the journals. A survey of the contents of the IUCr journals is given in Table 1. Details of each journal can be found in the reports below.

\section{J. R. Helliwell, Chair}

4.1.2. Acta Crystallographica Section A. Section A published 628 pages in 2003, very nearly the same as in 2002 (630). However, a closer look reveals a serious shrinkage of the volume of science published: the number of Research Papers and Short Communica- tions dropped from $65+14$ in 2002 to $57+6$ in 2003 , the number of pages devoted to these papers from 558 to 455 , the average length of a research paper from 8.1 to 7.7 pages. The only fortunate decrease to zero was in the number of obituaries. The difference of about 100 printed pages was balanced by an increase in reports (Executive Committee and IUCr General Assembly in Geneva) from 72 to 173. The reason for this preoccupying contraction may in part be attributed to the competition of other journals. An alternative reason may be found in the ongoing disappearance in many countries of many crystallography professorships and research groups and their replacement (at best) by service crystallographers.

The science published is of very high quality with many excellent papers in mathematics, new methods and philosophies of structure determination, charge-density research, diffuse scattering and disorder, dynamical theory, and electron crystallography. The rejection plus withdrawal rate at $20+20 \%$ is very high. The geographical distribution is reasonably balanced with 22 papers from North America, 24 from Europe (not including the Community of Independent States, CIS), 10 from CIS and 6 from Asia. The major omissions of the First World are Australia and Canada; South America has 1 paper. The average handling time has decreased to 4.5 months, with important differences between Co-editors, some of whom have handling times less than 2.5 months. Referees and authors are sometimes very slow in their responses, but the technical side has greatly benefited from the electronic submission system.

In the pipeline are two Special Issues: the Proceedings of the Third European Charge Density Meeting in Denmark, and an issue on Phase Transitions. There are also commitments for two Lead Articles. A promotion brochure has been published.

\section{Schwarzenbach, Editor of Section A}

4.1.3. Acta Crystallographica Section B. The 2003 statistics for Section B show that the numbers of articles and the numbers of pages are down from previous years. Between 1997 and 2003, the numbers of articles were 113, 106, 126, 137, 110, 132 (119 without the special issue) and 88 . The numbers of pages were 1,045, 943, 1,128, 1,127, 877, 1,088 (982 without the special issue) and 821 . The drop in pages after 2000 was a result of the decision to stop printing tables of atomic coordinates; there is no simple explanation for the drops in pages and articles in 2003.

The number of papers published in 2003 reporting inorganic structures was up $13 \%$ from 2002 , but the numbers of papers reporting metal-organic and organic structures were down by 44 and $41 \%$. It seems likely that competition from Crystal Engineering Communications (started in 1999 by the Royal Society of Chemistry) and Crystal Growth and Design (started in 2001 by the American Chemical Society) is a factor. Ways of reversing the trend are being considered. It is also possible that some papers that would in the past have appeared in Section B are now appearing in Section C.

The average length of a full paper was up from 8.6 and 8.9 pages in 2001 and 2002 to 9.8 pages in 2003. Reports of wonderful, complicated new science are appearing in Section B; these papers need to be long.

The impact factor of Section B rose again, this time from 1.96 to 2.03. The impact factor has risen each year since 1997, when it was 1.46.

The electronic submission system was implemented in early 2003; most papers are now submitted in this way. The system seems to be popular with authors, editors and the Chester staff. Time to publication (5.4 months) has dropped another month (down from 6.2 months in 2002 and 11.6 months in 1999). 
Table 1

Survey of the contents of IUCr journals.

Acta Crystallographica

\begin{tabular}{|c|c|c|c|c|c|c|c|c|c|c|c|}
\hline \multirow[b]{2}{*}{ Vol. } & \multirow[b]{2}{*}{ Year } & \multirow{2}{*}{\multicolumn{2}{|c|}{$\begin{array}{l}\text { Number } \\
\text { of pages§ }\end{array}$}} & \multirow{2}{*}{\multicolumn{2}{|c|}{$\begin{array}{l}\text { Number } \\
\text { of papers }\end{array}$}} & \multicolumn{3}{|c|}{ Full Articles $\dagger$} & \multicolumn{3}{|c|}{$\begin{array}{l}\text { Short } \\
\text { Communications: }\end{array}$} \\
\hline & & & & & & Numbe & & $\begin{array}{l}\text { Average } \\
\text { length }\end{array}$ & Number & $\begin{array}{l}\text { Avera } \\
\text { lengtl }\end{array}$ & $\begin{array}{l}\text { age } \\
\text { h }\end{array}$ \\
\hline A55 & \multirow{4}{*}{1999} & 1073 & \multirow{4}{*}{6472} & 122 & \multirow{4}{*}{1571} & 991 & \multirow{4}{*}{567} & 9.7 & 23 & 4.3 & \multirow{4}{*}{3.2} \\
\hline B55 & & 1128 & & 126 & & $113\}$ & & $9.6\}$ & 13 & 1.6 & \\
\hline C55 & & 2192 & & 929 & & 924 & & 2.4 & 80 & 4.4 & \\
\hline D55 & & 2079 & & 394 & & $394\}$ & & $5.4\}$ & 39 & 3.1 & \\
\hline A 56 & \multirow{4}{*}{2000} & 649 & \multirow{4}{*}{5678} & 82 & \multirow{4}{*}{1501} & 68 & \multirow{4}{*}{492} & 8.2 & 14 & 6.0 & \multirow{4}{*}{1.6} \\
\hline B56 & & 1127 & & 137 & & $124\}$ & & $8.6\}$ & 13 & 1.2 & \\
\hline C56 & & 2179 & & 943 & & 591 & & 2.8 & 352 & 1.3 & \\
\hline D56 & & 1723 & & 339 & & $300\}$ & & $5.3\}$ & 39 J & 2.4 & \\
\hline A57 & \multirow{5}{*}{2001} & 803 & \multirow{5}{*}{7162} & 103 & & 78 & \multirow{5}{*}{527} & 8.9 & 25 & 5.6 & \\
\hline B57 & & 877 & & 110 & & $100\}$ & & $8.6\}$ & 10 & 1.6 & \multirow{4}{*}{1.7} \\
\hline C57 & & 1504 & & 545 & 1948 & 541 & & $2.7^{\prime}$ & $4\} 85$ & 2.8 & \\
\hline D57 & & 1980 & & 390 & & $349\}$ & & $5.2\}$ & $41\}$ & 3.3 & \\
\hline E57 & & 1998 & & 800 & & 795 & & 2.5 & 5 & 1.7 & \\
\hline A58 & \multirow{5}{*}{2002} & 630 & \multirow{5}{*}{7905} & 102 & \multirow{5}{*}{2148} & 65 & \multirow{5}{*}{605} & 8.0 & 37 & 2.8 & \\
\hline B58 & & 1088 & & 132 & & $115\}$ & & $8.9\}$ & 17 & 1.1 & \\
\hline C58 & & 1570 & & 535 & & 531 & & 2.6 & 94 & 1.8 & 2.2 \\
\hline D58 & & 2243 & & 457 J & & $425\}$ & & $5.0\}$ & $32 J$ & $2.3 \mathrm{~J}$ & \\
\hline E58 & & 2374 & & 922 & & 918 & & 2.3 & 4 & 2.4 & \\
\hline A59 & & 628 & & 83 & & 58 & & 7.9 & 25 & 8.8 & \\
\hline B59 & & 821 & & 88 & & $81\}$ & & $9.8\}$ & 7 & 2.1 & \\
\hline C59 & 2003 & 1482 & 8735 & 482 & 2424 & 478 & 568 & 2.8 & $4\} 81$ & $2.2\}$ & 4.7 \\
\hline D59 & & 2385 & & 466 & & $429\}$ & & $5.2\}$ & 37 & $3.4 J$ & \\
\hline E59 & & 3419 & & 1305 & & 1297 & & 2.5 & 8 & 1.8 & \\
\hline
\end{tabular}

Journal of Applied Crystallography

\begin{tabular}{|c|c|c|c|c|c|c|c|c|c|}
\hline \multirow[b]{2}{*}{ Vol. } & \multirow[b]{2}{*}{ Year } & \multirow[b]{2}{*}{$\begin{array}{l}\text { Number } \\
\text { of pages }\end{array}$} & \multirow[b]{2}{*}{$\begin{array}{l}\text { Number } \\
\text { of papers }\end{array}$} & \multicolumn{2}{|c|}{ Full Articles } & \multicolumn{2}{|c|}{$\begin{array}{l}\text { Short } \\
\text { Communications } \dagger \dagger\end{array}$} & \multicolumn{2}{|c|}{ Short itemst+ } \\
\hline & & & & Number & $\begin{array}{l}\text { Average } \\
\text { length }\end{array}$ & Number & $\begin{array}{l}\text { Average } \\
\text { length }\end{array}$ & Number & $\begin{array}{l}\text { Average } \\
\text { length }\end{array}$ \\
\hline 32 & 1999 & 1208 & 192 & 126 & 7.9 & 28 & 4.5 & 38 & 1.9 \\
\hline 33 & 2000 & 1468 & 259 & 190 & 6.1 & 43 & 4.1 & 26 & 1.3 \\
\hline 34 & 2001 & 798 & 140 & 93 & 7.1 & 21 & 3.5 & 26 & 1.5 \\
\hline 35 & 2002 & 760 & 128 & 83 & 7.2 & 25 & 4.0 & 20 & 1.6 \\
\hline 36 & 2003 & 1505 & 282 & 225 & 5.9 & 26 & 3.8 & 31 & 1.7 \\
\hline
\end{tabular}

Journal of Synchrotron Radiation

\begin{tabular}{|c|c|c|c|c|c|c|c|c|c|}
\hline \multirow[b]{2}{*}{ Vol. } & \multirow[b]{2}{*}{ Year } & \multirow[b]{2}{*}{$\begin{array}{l}\text { Number } \\
\text { of pages§ }\end{array}$} & \multirow[b]{2}{*}{$\begin{array}{l}\text { Number } \\
\text { of papers }\end{array}$} & \multicolumn{2}{|c|}{ Full Articles } & \multicolumn{2}{|c|}{$\begin{array}{l}\text { Short } \\
\text { Communications }\end{array}$} & \multicolumn{2}{|c|}{ Short items } \\
\hline & & & & Number & $\begin{array}{l}\text { Average } \\
\text { length }\end{array}$ & Number & $\begin{array}{l}\text { Average } \\
\text { length }\end{array}$ & Number & $\begin{array}{l}\text { Average } \\
\text { length }\end{array}$ \\
\hline 6 & 1999 & 1209 & 69 & 57 & 8.1 & 2 & 2.0 & 10 & 2.2 \\
\hline 7 & 2000 & 419 & 65 & 58 & 6.6 & 4 & 2.8 & 3 & 1.3 \\
\hline 8 & 2001 & 1255 & 376 & 70 & 5.4 & 280 & 2.9 & 26 & 1.1 \\
\hline 9 & 2002 & 413 & 93 & 68 & 5.5 & 2 & 4.0 & 23 & 0.7 \\
\hline 10 & 2003 & 475 & 108 & 77 & 5.5 & 5 & 2.2 & 26 & 0.8 \\
\hline
\end{tabular}

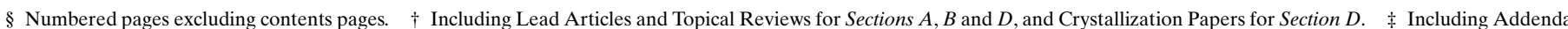

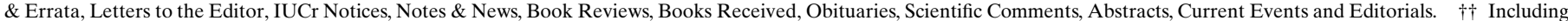

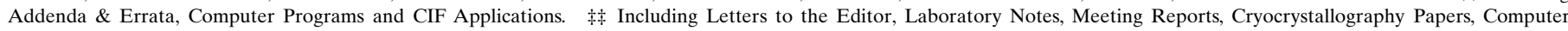

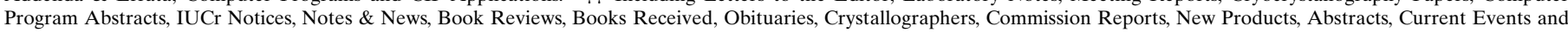
Editorials.

Special thanks are due to the Chester staff for their expert editorial work and for their ability to make pages with many tables, figures and footnotes look good. During 2003, Co-editor Å. Oskarsson retired after many years of fine service. We welcome new Co-editors D. L. Dorset and K. Ogawa to the Board.

\section{P. Brock, Editor of Section B}

4.1.4. Acta Crystallographica Section C. Section C continues to specialize in the rapid publication of high-quality papers with a significant Comment section and which will be of interest in the fields of chemistry, biochemistry, mineralogy, pharmacology, physics and materials science. Studies involving special techniques and difficult crystalline materials are also welcome. This past year has continued to see reductions in publication times for Section $\mathrm{C}$ submissions with 
the majority of technically correct and well written papers appearing online (http://journals.iucr.org/c) or in print within one or two months of submission. In 2003, Section C reported 49 inorganic papers, 186 metal-organic papers and 233 organic papers in a total of 1,482 pages. $39 \%$ of original technically acceptable submissions to Section C in 2003 were subsequently withdrawn or rejected; the principal reason for this withdrawal/rejection was that the reviewers were of the opinion that the Comment section did not provide significant added value to the numerical data freely available in the CIF. It would appear from this that numerous authors try for a Section $\mathrm{C}$ publication but are perfectly willing to resubmit to Section $\mathrm{E}$ when it is pointed out that the Comment section is not adequate for a Section $\mathrm{C}$ publication. Submission requirements for Section $\mathrm{C}$ are always under review and minor revisions were made to the Notes for Authors in response to various comments and suggestions from authors and Coeditors. The required author pre-checking of manuscripts has been made easier as described in Section 1.1 of Notes for Authors. Submissions that give rise to A-alerts during the pre-checking process can still be accepted for publication provided the authors give sound scientific reasons (via a validation report form as described in Section 1.1 of Notes for Authors) as to why the submission should be considered. A revised SHELXL-97 CIF template suitable for both Section $\mathrm{C}$ and Section E submissions is now available at http:// journals.iucr.org/c/services/authorservices.html. It was a pleasure to welcome Dr M. Helliwell as a new member of the Section C Editorial Board; I also thank the Co-editors, anonymous referees and the dedicated Chester staff for their invaluable assistance in the preparation of Section C.

\section{G. Ferguson, Editor of Section $\mathrm{C}$}

4.1.5. Acta Crystallographica Section D. Section D, subtitled Biological Crystallography, was established in 1993 to provide for the rapidly growing macromolecular crystallography community. The past year has been momentous for two reasons. First, the retirement at the end of 2002 of our inaugural Editor, J. P. Glusker, who played such a huge role in establishing the journal, led to the editorship being taken over by E. N. Baker and Z. Dauter at the beginning of 2003. Second, the celebration of 10 years of publication of Section D was marked by the commissioning of a series of special articles from prominent crystallographers. Four of these 10th anniversary articles were published in the December 2003 issue, and more will follow in 2004. The celebration of 50 years since the DNA structure was solved also provided an occasion to reflect on the enormous importance of biological crystallography.

Twelve issues of Section D were published in 2003, with the November issue being dedicated to the publication of the Proceedings of the CCP4 Study Weekend. The CCP4 meetings have assumed a very important role for the macromolecular community and they are now a major annual feature of Section D. The 2003 study weekend focused on experimental phasing. Anyone who has attended methods sessions at recent crystallographic meetings will vouch for the huge interest in this topic and the range of new approaches that are being developed. This collection of 20 articles, edited by A. McCoy and $\mathrm{N}$. McDonald, represents a very important resource. It is also available as a stand-alone publication.

Altogether in 2003, 457 articles were published. This figure is slightly misleading, as 247 of these were Crystallization Papers, which tend to be only 2-3 pages each. The remaining articles, most of them Research Papers (147) or Short Communications (31), accounted for about $70 \%$ of the 2,385 published pages. The place of Crystallization Papers has been much debated in recent years. Most of them are cited only once, and they therefore reduce the impact factor of the journal.
On the other hand, they contain valuable information on protein expression and purification, and the full details of crystallization experiments are essential to the reproducibility of the subsequent crystallographic analyses. Sometimes they also contain the key 'tricks' that make the difference in successful crystallization. We have taken the view that they are important to the community and should be published. Because the number of Crystallization Papers is increasing to the point where they may inhibit the further development of Section D, moves are under way to develop an electroniconly journal that will be a more appropriate venue.

Research articles were almost equally divided between those that reported new biological structures and those that focused on methods. Some do both, of course, and a notable feature in 2003 was several articles that described the successful solution of crystal structures with difficult twinning problems. Among the methods papers, several themes were apparent. In addition to the CCP4 issue on phasing, a number of papers presented successful efforts to obtain useful phase information from very small signals, such as from sulfur. The move to higher throughput crystallography has led to the development of new and powerful methods for automated map interpretation and model building, several of which were published in Section D in 2003. Although the number of protein structures of structural genomics targets published in Section D is still small, one outcome of structural genomics initiatives has been the development of comprehensive comparisons of success rates from different crystallization screens. A paper on this topic in the June issue, analysing the results of more than 320,000 crystallization experiments, may be the first of many.

Finally, the success of the journal depends on many people. First, it depends on the quality of the contributions it receives. Our goal for 2004 is to extend our capture of the best papers in a field that currently has many journals accessible to researchers. Publication times in Section D are now highly competitive and the quality of production is superb. We owe a particular debt to L. Jones, at Chester, and to the Co-editors and their reviewers. In particular, the Crystallization Co-editors, N. Chayen, A. Zagari, M. Pusey, M. Brzozowski and H. M. Einspahr have had a huge task and we owe them special thanks.

\section{E. N. Baker and Z. Dauter, Editors of Section D}

4.1.6. Acta Crystallographica Section E. Section E: Structure Reports Online has now completed its third year of operation and a total of 1,299 papers has been published in 2003, an increase of $41 \%$ over 2002. The distribution was as follows: inorganic 5\%, metalorganic $34 \%$ and organic $61 \%$. The major contributing countries were People's Republic of China 25\%, UK 10\%, USA 9\%, India 9\%, Germany $7 \%$, Japan 5\%, Malaysia $4 \%$ and Turkey $4 \%$. Papers were also received from another 55 countries.

Checking and editing of CIF files by authors has been assisted by the provision of enCIFer by the Cambridge Crystallographic Data Centre. A test version of printCIF for Word has also been made available by the IUCr to facilitate the preparation of text in the Microsoft Word environment.

To manage the large increase in the number of papers, a further six Co-editors were appointed in 2003: W. T. A. Harrison (UK), P. C. Healy (Australia), S. W. Ng (Malaysia), G. M. Rosair (UK), M. Weil (Austria) and C. Wilson (UK). This brings the total number of Coeditors to 23 .

The average time between receipt and on-line publication of manuscripts continues to be close to four weeks. About half of this is in the review and revision processes with authors and Co-editors, and half in the final editing, dealing with proofs and making the publi- 
cation available to readers. Around $15 \%$ of submissions are withdrawn or rejected. Mechanisms for transfer of appropriate papers between Sections C and E are well established. Some changes have been proposed in the handling of papers that generate serious checkCIF alerts, and these are being introduced in 2004 .

\section{W. Clegg and D. G. Watson, Editors of Section E}

4.1.7. Journal of Applied Crystallography. JAC published 1,505 pages in 2003 (496 pages for the Proceedings of the XIIth International Conference on Small-Angle Scattering held in Venice, Italy, in August 2002), an increase of regular contributions of about $33 \%$ compared with 2002, when 760 pages were published. The number of full articles (including 106 SAS articles) was 225 in 2003 (83 in 2002). The appointment of new Co-editors was probably the main reason for the increased interest of biologists, chemists, physicists and materials scientists to place their crystallography-based work in $J A C$. The seven new Co-editors who started their work in 2002 - A. J. Allen (USA), D. Chateigner (France), E. Dodson (UK), S. E. Ealick (USA), J. L. Hodeau (France), K.-I. Ohshima (Japan) and T. R. Welberry (Australia) - are to be congratulated. The positive trend continues with 216 manuscripts submitted in 2003 (at a combined rejection and withdrawal rate of about $25 \%$, the 2003 figure of published articles will be exceeded). Again, it is a pleasure to thank the Chester staff for handling ordinary and extraordinary matters with great patience and professionalism.

\section{G. Kostorz, Editor of JAC}

4.1.8. Journal of Synchrotron Radiation. JSR published 77 articles and a total of 475 pages in the six issues produced in 2003. We expect these numbers to increase next year as the number of manuscripts submitted in 2003 was up by $17 \%$ over the previous year. Selected papers from two international workshops (XIV Russian Synchrotron Radiation Conference SR2002 held in Novosibirsk, Russia, and BioXAS and Structural Genomics held at LURE, Orsay, France) were accepted for publication. We believe that the publication of selected papers from workshops is an important service to the synchrotron-radiation community and we plan to continue this.

Several informal discussions were held throughout the year among the Main Editors and Co-editors concerning issues such as increasing subscription rates and expanding the awareness of the synchrotronradiation community to $J S R$. One outreach activity initiated in 2003 was the development and distribution of an advertisement flyer to increase the visibility of the journal.

Å. Kvick, D. M. Mills and T. Ohta, Editors of JSR

\subsection{Commission on International Tables}

First of all, the members of the Commission wish to express their deep gratitude to Th. Hahn, who retired as Chair of the Commission. He will, however, continue to act as Editor of Volume A. At the end of 2003, H. Fuess was appointed as the new Chair of the Commission.

Th. Hahn guided the Commission during two periods (1972-1981 and 1993-2003). His achievements during that time (the six Volumes A through F) are extremely impressive and place a certain burden on his successor. Volume D was published in December 2003. The remaining Volumes A1 and G will be published during 2004 and 2005, completing the whole series. At the request of the Executive Committee, the Commission has begun to explore the technical and business issues relating to the online distribution of the International Tables series. Following an initial planning meeting between the Chair and the editorial staff in Chester, a working model is currently under development. This will include all volumes as soon as they are technically ready. Technical details have been decided by a working group composed of S. R. Hall (Perth, Australia, Chair), H. D. Flack (Geneva, Switzerland), and B. McMahon and P. R. Strickland from the IUCr office in Chester.

The home page of the Commission is maintained at Tel Aviv University by U. Shmueli at the URL http://crystal.tau.ac.il/xtal/ comit/index.html. Given below are the sales and stock figures of all published volumes as at 31 December 2003.

\begin{tabular}{llllllll} 
& \multicolumn{9}{c}{$\begin{array}{c}\text { Brief } \\
\end{array}$} & Vol. A & Vol. A & Vol. B & Vol. C & Vol. D & Vol. E & Vol. F \\
\hline First published & 1983 & 1985 & 1993 & 1992 & 2003 & 2002 & 2001 \\
Sales in 2003 & 345 & 310 & 127 & 155 & 285 & 271 & 234 \\
$\begin{array}{l}\text { Total sales } \\
\text { Stock at 31 }\end{array}$ & 9,636 & 6441 & 2,953 & 3,532 & 285 & 333 & 1,147 \\
$\quad \begin{array}{l}\text { December } \\
\quad \text { 2003 }\end{array}$ & 509 & 491 & 600 & 0 & 1,166 & 404 & 827
\end{tabular}

4.2.1. Volume A. Space-Group Symmetry; Editor Th. Hahn. The fifth edition of Volume A and the Teaching Edition of Volume A appeared in the spring of 2002. Since then, corrections of errors and suggestions for small improvements have been collected. Discussions have been held as to whether additional subsections of Volume A (e.g. noncentric space groups for protein crystallographers) might be a suitable addition.

4.2.2. Volume B. Reciprocal Space; Editor U. Shmueli. The editorial activities during 2003 were mainly dedicated to the preparation of the third edition of Volume B, based on the following timetable: (i) target date for publication: mid-2006, (ii) start of technical editing: mid-2005, and (iii) deadline for submission of revised and new contributions: end of 2004.

Several authors of major chapters expressed their intention to introduce significant changes, and four new authors have been invited. At the time of writing this report, all the invitations have been accepted. Additional details will be presented on the home page of the Commission (see above).

4.2.3. Volume C. Mathematical, Physical and Chemical Tables; Editor E. Prince. The Third Edition of Volume C was prepared by E. Prince and was published in 2003, with corrections and revisions of a total of 11 chapters. Professor Prince has retired as the Editor and the warmest thanks of the Commission and the community of crystallographers are due to him.

4.2.4. Volume D. Physical Properties of Crystals; Editor A. Authier. The Commission is grateful to A. Authier for the completion of Volume D, which is a tremendous achievement not only for crystallographers and mineralogists but also for all scientists interested in the solid state and in materials science. The volume contains an original presentation of twinning and phase transitions, which may be used together with the accompanying software.

4.2.5. Volume E. Subperiodic Groups; Editors V. Kopsky and D. B. Litvin. The volume has been on sale since 2002. Errors and corrections are being collected.

4.2.6. Volume F. Macromolecular Crystallography; Editors M. G. Rossmann and E. A. Arnold. Volume F turned out to be a solid base for people working on the structure determination of biological macromolecules. The volume continues to sell well and a second edition has to be considered soon.

4.2.7. Volume G. Definition and Exchange of Crystallographic Data; Editors B. McMahon and S. R. Hall. In cooperation with COMCIFS, the IUCr Committee for the Maintenance of the CIF Standard, a revision cycle on a number of CIF dictionaries during 2003 was linked to the production schedule of the volume, and the descriptive chapters relating to those dictionaries amended accord- 
ingly. By early 2004, the outstanding chapters for the applications section of the volume were entering the review process, and the complete manuscript is expected to be with the editorial office by Easter 2004.

4.2.8. Volume A1. Maximal Subgroups of Space and Plane Groups; Editors H. Wondratschek and U. Müller. The volume has been submitted to the Chester office and technically edited. Proof reading is in progress and the entire volume will go to print in 2004.

H. Fuess, Chair

\subsection{Commission on Aperiodic Crystals}

The activities of the Commission were focused on the organization of international conferences and the coordination of activities between the different communities working on quasicrystals and incommensurate structures.

On 8-13 September, the International Congress on Aperiodic Crystals, Aperiodic 2003, took place at the Federal University of Minas Gerais in Belo Horizonte (Brazil). This meeting was organized by N. Speziali. Aperiodic 2003 was the eighth in a series of triennial meetings that have the goal to bring together scientists studying the atomic structures and physical properties of quasicrystals, incommensurately modulated crystals, incommensurate composite crystals and polytypes. It was attended by 90 participants from 22 countries in 5 continents. Participation was negatively affected by travel difficulties that have existed during the past few years. At least two intended participants, both of them invited speakers, could not come to Belo Horizonte because they did not obtain transit visas for the USA in time. The proceedings of Aperiodic 2003 will be published as a Special Issue of the journal Ferroelectrics. A detailed report of this meeting can be viewed on the web site of the Commission.

The Commission continued to promote activities on the crystallography of aperiodic crystals at national and international meetings. A microsymposium on Incommensurate Crystals was organized at the ACA meeting in Covington, Kentucky, USA (26-31 July 2003) by R. Staples (Chair) and the Special Interest Group on Service Crystallography. The interest of service crystallographers in the crystallography of incommensurately modulated and composite crystals shows that this type of crystalline order is encountered increasingly often in synthetic studies and pervades all of chemistry. Speakers were C. Campana, S. Schmid, O. Gourdon, B. Campbell, L. Daniels and G. Borgstahl.

A lecture on incommensurate crystals was presented by N. Speziali at the XVI Meeting of the Brazilian Society of Crystallography (SBCr) (March 2003, São Paulo, Brazil).

At the Asian Crystallographic Meeting AsCA'03/Crystal-23 (10-13 August 2003 in Broome, Australia), a session on Modulation, Disorder and Twinning was chaired by V. Young and S. Schmid. Speakers were H.-B. Bürgi, T. R. Welberry, S. Schmid and M. Onoda.

At the European Crystallographic Meeting ECM-21 (24-30 August 2003 in Durban, South Africa), a microsymposium on New Developments in the Field of Aperiodic Crystals was chaired by G. Chapuis and W. Steurer. Speakers were R. McGrath (Liverpool, UK) and H. Klein (Grenoble, France) on quasicrystals and J. Darriet (Bordeaux, France) and M. Valkeapää (Göteborg, Sweden) on composite oxides.

The series of workshops on aperiodic crystallography in Bayreuth, Germany, was continued by the 4th Workshop on Structural Analysis of Aperiodic Crystals, University of Bayreuth, 6-8 March 2003, organized by S. van Smaalen. Approximately 40 participants attended lectures on structure determination, symmetry aspects, and the interpretation of structures by M. Dusek and V. Petricek (Prague,
Czech Republic), J.-M. Perez-Mato (Bilbao, Spain), A. Schonleber (Lausanne, Switzerland), and L. Palatinus and S. van Smaalen (Bayreuth). In the afternoons, the participants had the opportunity to practise the structural analysis of incommensurate crystals with the computer program JANA2000 and a script with several worked-out examples that treated different aspects of structure solution and structure analysis.

As part of the Asian Crystallographic Meeting AsCA'03/Crystal-23 in Broome, Australia (10-13 August 2003), a half-day workshop on Introduction to Modulated Structures was organized by S. Schmid. It was attended by 17 participants from Australia, India, Japan, Singapore, Taiwan, Thailand and the USA.

A meeting of the Commission took place during the conference Aperiodic 2003 in Belo Horizonte, Brazil. Among other points discussed, the proposal to organize Aperiodic 2006 in Japan was unanimously accepted. Aperiodic 2006 will be organized by A. Yamamoto (Chair), A. P. Tsai (Vice-Chair), Y. Gotoh, Y. Michiue, Y. Miyasaki and K. Saitoh.

The Commission maintains internet pages at the web site of the IUCr at http://www.iucr.org/iucr-top/comm/capd/index.html. A web site on all aspects of the crystallography of aperiodic crystals is maintained by the special interest group (SIG) on aperiodic crystals of the European Crystallographic Association. It is maintained by M. Dusek (Prague, Czech Republic), and may be found at http:// www-xray.fzu.cz/sgip/aphome.html.

S. van Smaalen, Chair

\subsection{Commission on Biological Macromolecules}

Active support from the Commission has been sought for a number of scientific meetings and specialized workshops in Asia, Europe and South America to be held in 2004 and 2005. In general, these have been enthusiastically received subject to some questions of timing and access.

The principal activity of the IUCr currently affecting the structural biology community is the proposal for a new journal: Acta Crystallographica Section F. This will be all-electronic for rapid publication of structural genomics, protein structures and crystallization results. A final decision as to whether to proceed will be made by the IUCr Executive Committee based primarily on the business plan for the enterprise which has been presented to them. In order to facilitate publication of protein crystal structures, independently of the move to a new electronic section of Acta Cryst., H. M. Einspahr is working closely with the Protein Data Bank to coordinate the deposition of data with publication of structures.

In the past year, very successful meetings of the Asian and European Crystallographic Associations were held in Australia and South Africa, respectively. Each of these attracted large numbers of young scientists in the area of structural biology. The first Protein Data Bank prizes for student presentations for each of the associations were made at these meetings. The exotic venues were an added bonus for those lucky enough to attend the meetings.

\section{J. M. Guss, Chair}

\subsection{Commission on Charge, Spin and Momentum Densities}

The main activity was the Sagamore XIV meeting held in Broome, Australia. The other important event was the third European Charge Density Meeting (ECDM-3) coupled with a PESC Workshop on New Information from Modern Charge Density Studies held at the Aarhus University conference centre Sandbjerg Estate, Denmark. 
(1) Sagamore XIV Charge, Spin and Momentum Density Meeting, Broome, Australia, 13-18 August 2003

The Sagamore meetings are one of the most important 'outcomes' of the Commission, and Sagamore XIV, organized and chaired by M. Spackman, was another highly successful meeting in this series. This, the fourteenth of these triennial meetings, followed a joint meeting of the Asian Crystallographic Association and the Society of Crystallographers in Australia and New Zealand (AsCA'03/Crystal-23) at the same location. The Sagamore meetings focus on aspects of charge, spin and momentum distributions, their determination from a wide variety of experimental techniques, and their detailed analysis and comparison with theory, and have a considerable history, recently documented by M. J. Cooper (http://alpha.uwb.edu.pl/sagamore/ page_history.html).

The meeting attracted 85 participants, which was somewhat down on previous meetings, but very pleasing considering the remoteness of the location. Nearly $50 \%$ of participants came from either Australia or Japan, and 14 countries were represented overall. Because the meeting followed the larger AsCA'03/Crystal-23 meeting, the participants benefited from the substantial sponsorship provided, especially from the IUCr (for young scientist attendance), and from Marresearch, Bruker Nonius and Rigaku/MSC. As usual at Sagamore meetings, oral presentations were a mixture of key invited lectures and talks selected from submitted abstracts. As noted at earlier meetings, presentations generally contained more physics than chemistry, but compared to the previous Sagamore XIII there was much greater participation from the charge density, neutron and electron diffraction communities, and it was pleasing to see a greater number of theoreticians.

Sessions were arranged into a small number of key topics: chargedensity studies on heavy-atom materials, instrumentation, new approaches to measuring magnetization densities, inelastic scattering, new perspectives in theory and computation, density matrices and electron densities, pushing the limits of experimental charge densities, spin densities, electron momentum spectroscopy, electron scattering techniques, Compton scattering, and the state-of-the-art in topological analysis of charge densities. The proceedings will be published as a special issue of Journal of Physics and Chemistry of Solids.

(2) PESC Workshop on New Information from Modern Charge Density Studies, Sandbjerg Estate, Denmark, 26-29 June 2003

Direct outcomes of the workshop were (1) the formation of a new European network spanning 11 countries of research groups active in charge density studies and (2) publication of the Proceedings of the Workshop in a Special Issue of Acta A.

The workshop was organized by F. K. Larsen and B. Iversen and took place at the Aarhus University Sandbjerg Estate; these facilities provided an excellent setting for stimulating scientific discussion. The PESC workshop was organized together with the Third European Charge Density Meeting (ECDM-3), which preceded the workshop (24-26 June). The rationale of this construction was to offer a fullscale meeting in which both the established charge-density community and newcomers from related fields could meet. The PESC workshop had 22 invited lecturers, some of which, at their own expense, also took part in the preceeding ECDM-3 meeting; many ECDM-3 participants stayed on for the PESC workshop. A total of 65 participants was involved in the arrangement.

The scientific programme consisted of four half-day sessions, an opening lecture and poster presentations. The opening lecture was given by P. Coppens discussing the complementary nature of, but also mutual interdependence of, experimental and theoretical chargedensity methods.
In the first session, the main theme was chemical bonding and reactivity determined by experimental charge-density studies. The second session was on theoretical charge-density studies. The session was wrapped up by D. Gatteschi, who opened eyes to potential new applications of charge-density methods in the field of molecular magnetism - a highly visible area of modern nanoscience. The third morning session was dedicated to magnetism in relation to charge and spin densities The concluding session consisted of six talks intended to show the road to the future with presentation of novel experimental techniques. The meeting was closed by C. Lecomte who reminded everyone that all the technical advances in X-radiation, computer power, detectors, interpretation tools etc. must not cause us to forget traditional merits: random application of charge-density methods in emerging fields must parallel continued methodological research on the basic development of the X-ray method.

(3) ECDM-3 (http://www.chem.au.dk/ ECDM-III/Program.htm)

The first day focused on the updates of the usual software packages used in charge- and spin-density refinements: multipole analysis and molecular properties (Valray, MollyN, XD, Mopro, WinXPR02003); topological analysis (Integrity, Tonto); MEM. The following sessions dealt with intermolecular interactions, transition-metal complexes and photo-crystallography. Many stimulating discussions occurred at the end of each session and until late into the night.

(4) A new Sagamore project

D. Jayatilaka proposed the following project: Constrained wave function refinement with the overall aim to see if the constrained wave function method can be 'routinely' used for charge-density analysis by experimental groups. (The project was launched at the Gordon Research Conference in July 2004.)

\section{Lecomte, Chair}

\subsection{Commission on Crystal Growth and Characterization of Materials}

The Commission was actively engaged during 2003 in the promotion and organization of schools aimed at the diffusion of this scientific discipline among young scientists, particularly from developing countries. The following list gives an idea of the events in which the Commission was involved.

(1) The International School on the Crystal Growth of Technologically Important Electronic Materials (ISCGTIEM) was organized by K. Byrappa and R. Fornari at the University of Mysore, India, 20-27 January 2003. The school was supported financially by the IUCr, through a grant that allowed the participation of 15 needy students. The school had about 90 students and 30 tutors from 20 different countries, representing all five continents. All participants received a copy of the book entitled Crystal Growth of Technologically Important Electronic Materials, edited by K. Byrappa, T. Ohachi, H. Klapper and R. Fornari, and published by Allied Science Publishers, New Delhi, India. Ten members and consultants of our Commission participated in the school as lecturers, which provided an excellent opportunity for planning future Commission activities, as well as for discussing topics of potential interest for the Florence Congress in 2005.

(2) The International School on Crystal Growth, Characterization and Applications (ISCGChA) was held in La Pedrera, Uruguay, 9-13 December 2003 and chaired by L. Fornaro. The objective of ISCGChA was to foster activities connected with the growth and characterization of crystals, especially in Latin American countries. ISCGChA was aimed at promoting the training of young students and researchers in the principles and the methods of crystal growth, and 
in the different characterizations and applications of crystals. ISCGChA included a series of lectures from European, Japanese, North American and Latin American lecturers as well as poster sessions, where the participants presented their activities. The presentations of Latin American participants will appear in a Special Issue of Crystal Research and Technology. The school was attended by about 60 participants. Two members of the Commission gave lectures at the school, while two additional Commission members were involved in the International Advisory Committee.

The Commission also discussed the events that may deserve support in 2004-2005. Among the various proposals, it was decided that the following schools/conferences would be actively supported by the Commission, which at the same time proposed that these events should be financially sponsored by the IUCr:

(i) 12th International Summer School on Crystal Growth, Berlin, Germany, 1-7 August 2004, held under the auspices of the International Organization of Crystal Growth;

(ii) 14th International Conference on Crystal Growth (ICCG-14) in conjunction with the 12th International Conference on Vapor Growth and Epitaxy (ICVGE-12), Grenoble, France, 9-13 August 2004;

(iii) International Workshop on Nanomagnetism, to be held in Havana, Cuba, 14-18 November 2004;

(iv) International School on Crystal Growth: Fundamentals, Methods and Applications to Biological and Nano Crystals, Puebla, Mexico, March 2005. This school is directly promoted by the Commission.

A detailed report about these events will be provided before the Florence Congress in 2005.

R. Fornari, Chair

\subsection{Commission on Crystallographic Computing}

The activities of the Commission included:

(1) the preparation of proposals for computing-related sessions during the Florence Congress;

(2) preliminary work related to the crystallographic computing school to be organized in Siena, prior to the Florence Congress;

(3) two issues of a Newsletter (http://www.iucr.org/iucr-top/comm/ ccom/newsletters), edited by Commission member L. M. D. Cranswick.

A. L. Spek, Chair

\subsection{Commission on Crystallographic Nomenclature}

The activity of the Commission is through its working groups.

(1) Working Group on Synchrotron Radiation Nomenclature (D. M. Mills, Chair). The group has produced a draft report with some recommendations regarding the uses of the terms 'brilliance' and 'brightness'. The draft report is presently under discussion by the members of the Commission.

(2) Working Group on Phase Identifiers (I. D. Brown, Chair). The working group charged with developing an identifier for crystalline phases has examined a number of ways to formulate an identifier that will uniquely label crystal structure phases stored in a computer database. It has listed the properties that should under normal circumstances uniquely characterize each crystalline phase and has recently coordinated its efforts with the committee developing an IUPAC Chemical Identifier (IChI) since it was the members of this committee who initially requested the phase identifier. Both groups independently adopted very similar approaches and work is now proceeding in cooperation with the IChI group in order to incorporate the crystallographic phase information into IChI. The final report is expected to be submitted during 2004.

(3) Working Group on Co-Crystal Nomenclature (F. H. Allen, Chair). The group has been established to examine the nomenclature of co-crystals, for which a wide variety of terminologies currently exists, e.g. inclusion compound, clathrate, molecular complex, adduct, etc. The Chair reports that there was actually little input from the members of the working group throughout the year, which shows a certain lack of interest in the topic. The question is therefore whether the activities of the working group should be pursued in their present form. Furthermore, due to the additional responsibilities he has had to take up recently, F. H. Allen has asked to be relieved of his position as Chair. If, however, a member of the Commission feels that the topic should not be dropped, could he/she suggest a new Chair and, eventually, a new formulation of the topic that might be more stimulating.

(4) The IUCr representative on the IUPAC Interdivisional Committee on Terminology, Nomenclature and Symbols, S. C. Abrahams, reports that membership activity was relatively low during the year but is expected to rise with the appointment of a new Chair and a new Secretary. The number of IUPAC technical reports received and reviewed was unusually small. A better name for the unified atomic mass unit, symbol u, received considerable discussion. Subsequently, the Comité Consultatif des Unités (CCU) decided to introduce the Dalton, symbol Da, into Table 7 of its brochure entitled The International System of Units in the next (8th) edition, due 2004/ 2005; this accords it equal status with the unified mass unit, defined as $m\left({ }^{12} \mathrm{C} / 12\right)$. It seems that the $\mathrm{CCU}$ plans to replace the unified atomic mass unit by the Dalton but will do so over a period of time.

(5) The Chair of COMCIFS, I. D. Brown, reports that no nomenclature issue has arisen during the year. In preparing CIF dictionaries, COMCIFS has to define concepts very tightly and to invent CIF names for these, but the CIF names are not suitable for every day use and so do not raise any nomenclature issues. The items that were defined this year were likewise all straightforward and have not raised any fundamental issues of nomenclature:

\section{A. Authier, Chair}

\subsection{Commission on Crystallographic Teaching}

No report has been received from the Chair.

\section{R. B. Neder, Chair}

\subsection{Commission on Electron Diffraction}

As the boom in nanoscience continues, the past year has been a remarkable year for electron diffraction. Especially notable, following the award of the Nobel Prize to A. Zewail, has been the growth of time-resolved electron diffraction in the gas phase, with pulse durations now down to $400 \mathrm{fs}$. While Coulomb interactions limit speed compared to pulsed X-ray work, count rates are much higher. Fast electron-microscope imaging, still at the nanosecond timescale, is now also growing with a large new programme at Livermore Laboratories, California, USA. An equally remarkable highlight from the past year is the publication of the first atomic-resolution image of a carbon nanotube (Science, 300, 1419). This aberration-free 'lensless image' was obtained almost entirely from the electron diffraction pattern of a single tube, using new iterative phasing methods that can now solve the phase problem for non-periodic objects. Throughout the world, scientists are placing orders for the new generation of 
aberration-corrected electron microscopes, which, together with the new electron monochromators for energy-loss spectroscopy, promise to revolutionize the field. (In the USA, the Department of Energy 'TEAM' project plans to install these in several national laboratories over the next few years, for example.) In biology, the appearance of TEMs dedicated to liquid-helium-cooled cryomicroscopy for singleparticle three-dimensional imaging of proteins that cannot be crystallized is producing major advances, and the automation of electron tomography proceeds apace in both materials science and biology. The publication of the first subnanometre-resolution, three-dimensional views inside a mesoporous silicate catalyst must also rank as one of the year's highlights. The year has seen many conferences devoted to electron diffraction and imaging, including MC2003 in Dresden, Germany (7 September 2003), the Frontiers of Electron Microscopy conference in Berkeley California, USA (5 October 2003), a workshop in Cairns, Australia (30 June 2003) on the noncrystallographic phase problem, a conference honoring J. M. Cowley, FRS, in Arizona, USA (3 January 2003), the Moscow electron crystallography school, a diffraction school in Delft, The Netherlands (22 January 2003), the Microscopy Society of America meeting (3 August 2003), the UK EMAG meeting in Oxford (3 September 2003), a school on advanced HREM in China at the end of 2002 (see below, not reviewed last year) and several conferences in Japan, amongst many others.

\section{NCEM Electron Diffraction School, 19 April 2004}

About 20 students, postdocs and industrial researchers attended a week-long school on electron diffraction at the National Center for Electron Microscopy at Lawrence Berkeley Laboratory, Berkeley, California, USA, starting on 19 April 2004. Lectures by L. Marks, J. Zuo, W. Sinkler, J. C. H. Spence, U. Dahmen, A. Eades and R. Kilaas covered all aspects of electron crystallography, including CBED, $\mathrm{SAD}$, diffuse scattering, powder patterns for phase identification, combining SAD with HREM, and basic theory, from dynamical theory, Bloch waves, channelling and multislice, to direct methods. Special topics included diffractive imaging and the precession camera. Afternoons were devoted to practical classes and computer use for simulations. One set of programs for most electron crystallography purposes, now executable on the web for all to use, may be found at http://emaps.mrl.uiuc.edu/. A similar school may be held in 2005.

Advanced High-Resolution Electron Microscopy, 23 December 2002

There were in total 100 Chinese participants attending the workshop/school. Among them three were from other countries, five were from Taiwan and one from Hong Kong. Ten experts were invited to give main lectures: Jiang-hua Chen (Delft University, The Netherlands), Jin Zou (Sydney University, Australia), Di Wang (Fritz-Haber Institute, Berlin, Germany), Fu-rong Chen (Tsinghua University, Taiwan), Rong Wang (Peking University of Science \& Technology, People's Republic of China), Xiao-jing Wu (Fudan University, People's Republic of China), Man-ling Sui [Institute of Metals, Chinese Academy of Sciences (CAS)], Hai-fu Fan, Fang-hua Li and Huai-bin Wang (Institute of Physics, CAS). The workshop/school aimed at offering a forum to communicate new theories and new methods in investigating crystal structures and microstructures with a resolution higher than the resolution of the electron microscope. The topics of this workshop/school mainly concentrated on solving the inverse problem in high-resolution electron microscopy (HREM) by image processing. Two image processing techniques that were studied most extensively in the People's Republic of China and Europe, respectively, and the technique recently developed in Taiwan were introduced including theories, methods and applications. This indi- cated a new prospect in the application of HREM. In addition, the advantages and problems of spherical-aberration-corrected HREM were discussed.

This workshop/school offered a good opportunity to all participants to learn about the fundamental theory and/or recent advances in the field of HREM, and also to report their achievements.

\section{J. C. H. Spence, Chair}

\subsection{Commission on High Pressure}

The main objective of the Commission is to promote and coordinate advances and new developments in crystallographic applications of high-pressure science. Special emphasis is given in helping new and/or young scientists with their specific scientific problems to be able to use high pressure as one of the tools to answer their specific structural questions and in turn to contribute with their work to the development of high-pressure crystallography. As the main tools to achieve this goal, the Commission organizes workshops in each of the two years between the triennial IUCr Congress. In 2003, this workshop was organized at the Lawrence Berkeley National Laboratory and sponsored jointly by LBL, the NSF-sponsored Consortium for Materials Properties Research in Earth Sciences (COMPRES) and the IUCr. In addition to the 'regular' workshop, the Commission for the first time helped to organize a crystallography summer school held in Erice, Italy.

Erice Summer School

The High-Pressure Crystallography course was organized as the 34th Crystallographic Course of the Euro Summer School and simultaneously a NATO Advanced Science Institute at the Ettore Majorana Centre, Erice, Sicily, 4-15 June 2003. It was the first HighPressure School organized by the Commission, fully dedicated to young scientists interested in entering into the field or developing their skills after some years of carrying out their high-pressure research. The idea of this course originated in 1998 in the Commission. Initially, it was planned to be held in Warsaw, Poland, to coincide with the High-Pressure Courses that have been organized there since 1995, but it was later moved to Erice in order to embed it into the Euro Summer School. A. Katrusiak of the Adam Mickiewicz University in Poznan, Poland, and P. F. McMillan of London University College, UK, acted as course directors. The local organization and additional support were provided by L. Riva di Sanseverino (University of Bologna, Italy) and P. Spadon (University of Padova, Italy), who are gratefully thanked. 120 participants attended the course. 45 lectures were given by M. I. McMahon, R. J. Angel, J. B. Parise, A. Katrusiak, J. S. Loveday, P. F. McMillan, M. Mezouar, O. Shimomura, V. Petricek, B. Winkler, J. S. Tse, A. R. Oganov, W. B. Holzapfel, L. Pusztai, J.-P. Itie, A. Armigliato, M. Szafraski, M. Paz-Pasternak, I. N. Goncharenko, F. Rodriguez, S. S. Batsanov, L. Dubrovinsky, V. L. Solozhenko, A. Gauzzi, V. F. Degtyareva, N. L. Ross, W. F. Kuhs, E. V. Boldyreva, G. Krauss, R. Fourme and S. M. Gruner.

Apart from the lectures, there were ten workshops focusing on the practical aspects of the theoretical calculations for high-pressure research, and there were experiments in either in-house laboratories or national and international research facilities. These workshops were overbooked by the students and additional meetings with the tutors had to be arranged. Two poster sessions presented nearly 70 posters and provided an additional forum for discussions. The school was also transmitted live on the internet. This forum was used by several dozen participants, who contributed questions and answers to the discussions via the chat-room. 
The programme and the organization of the course were evaluated very positively by the participants. We are very grateful for the financial support for young scientists from the IUCr.

2003 IUCr High-Pressure Workshop, LBL, Berkeley

The regular Commission workshop was organized at the Lawrence Berkeley National Laboratory (LBL) in Berkeley, California, USA, 4-7 December 2003. This year's workshop focused on the theme NonAmbient Crystallography: The Science of Change and was sponsored jointly by the IUCr, LBL, COMPRES and NSF. The organization of the workshop was headed by S. Clark (LBL, COMPRES), A. Kavner (UCLA, COMPRES) and S. Tolbert (UCLA and Commission member).

In addition to a range of interesting microsymposia (anisotropy in $P / T$ deformations; kinetics of structural change; theory of structure under pressure; transport under pressure; phase transitions; synthesis at high pressure), this year's workshop also offered four hands-on introductory workshops on: high-pressure infrared spectroscopy; high-pressure powder diffraction; laser-heated diamond-anvil cells; and general alignment and maintenance of diamond-anvil cells. These workshops greatly benefited from the infrastructure of the hosting ALS. As usual for the IUCr high-pressure workshops, the oral lectures were also complemented by two poster sessions. The workshop attracted more than 80 participants. Thanks to the support of IUCr and NSF, a total of 20 young scientists benefited from travel support.

\section{Home page}

The Commission's home page is maintained by Commission member J. Loveday and continues to update the high-pressure community on information on software, future and past meetings, central facilities, scientists and publications in the high-pressure field. The home page can be accessed at http://www.iucr.org/iucr-top/comm/ chp/index.html.

\section{Future meetings}

Part of the Commission's activity in 2003 related to upcoming meetings in 2004 and 2005. In 2004, the Commission is organizing another IUCr high-pressure workshop, this time at the new Canadian synchrotron-radiation facility in Saskatoon. Commission member J. Tse is heading the organization for the event, taking place 18-21 August. In addition to this, the Commission spent time in putting together a draft proposal for an interesting high-pressure programme for the up-coming Florence Congress in 2005. J. B. Parise represents the Commission on the Programme Committee. The Commission proposes six microsymposia to be held on six succeeding half-days. According to this proposal, the Commission will also nominate a Keynote Lecturer for each of these three days.

\section{Kunz, Chair}

\subsection{Commission on Inorganic and Mineral Structures}

The contacts among the members and consultants of the Commission have been maintained mainly by e-mail and via the web site at http://www.lcm3b.uhp-nancy.fr/cims/ administered by consultant member M. Nespolo. Some members (G. Ferraris, L. B. McCusker, E. Tillmanns, A. M. Glazer and M. Nespolo) met on the occasion of ECM-21 in Durban, South Africa, 24-29 August 2003. On that occasion, after some discussions with the IUCr President, it was realized that it would be impossible to organize a meeting sponsored by the IUCr in 2005 because it would clash with the Florence Congress. Thus, the proposal of organizing a materials-scienceoriented symposium in Singapore (as satellite of ICMAT 2005) was abandoned and the Chair was authorized to explore the possibility of organizing instead a meeting in Italy. This eventually came to reality in the form of a meeting entitled Micro- and Mesoporous Mineral Phases - Mineralogical, Crystallographic and Technological Aspects, which will be held in Rome, Italy, 6-7 December 2004, with substantial financial support from the Italian National Academy of Lincei (applications for financial support have been submitted to other institutions, first of all to the IUCr); some members of the Commission will contribute as invited speakers.

In 2003, the following meetings have been supported by the Commission and received funds from the IUCr:

XV International Conference on X-ray Analysis and Crystal Chemistry of Minerals, St Petersburg, Russia, 15-19 September 2003.

Fedorov Session 2003, St Petersburg Mining Institute, Russia, 9-10 December 2003.

Members of the Commission attended both meetings as invited speakers; other members were active as Chairs of microsymposia and speakers at ECM-21.

The following members have reported to the Chair activity related to the CIMS purposes:

D. Pushcharovsky represents the Commission on the Programme Committee of the Florence Congress.

L. B. McCusker is a member of the Advisory Board for the 14th International Zeolite Conference (Cape Town, South Africa, 25-30 April 2004) and maintains web sites with data on zeolites.

M. Nespolo is the organizer of the satellite meeting of ECM-22 entitled Crystallography at the Start of the 21st Century: Mathematical and Symmetry Aspects (Budapest, Hungary, 24-26 August 2004), where the Commission will be responsible for one session.

M. Matsui is Chair of the Meeting Secretariat for IMA-2006 (Kobe, Japan, 23-28 July 2006).

G. Ferraris is convener of the microsymposium Microstructures, Modularity, Modulations in Minerals at the 32nd International Geological Congress, Florence, Italy, 20-28 August 2004, and coauthor (with E. Makovicky and S. Merlino) of the IUCr monograph Crystallography of Modular Materials.

G. Ferraris, Chair

\subsection{Commission on Neutron Scattering}

A few members of the Commission met at the 3rd European Conference on Neutron Scattering (ECNS), Montpellier, France, 3-6 September 2003, but no formal meeting was organized. The Walter Hälg Prize for European scientists performing outstanding work on neutron scattering with long-term impact on scientific and/or technical neutron scattering applications was awarded to R. A. Cowley. He was honoured for his pioneering experiments with neutrons and $\mathrm{X}$-rays and, in addition, for his publications on theory. The main topics at ECNS were instrumentation, novel concepts for nextgeneration neutron sources, magnetism, as well as biophysics and functional materials. Within the range of interest of the Commission, the planning for the Florence Congress was discussed, as well as the important EU Infrastructure Support for the neutron and muon centres in Europe (Integrated Infrastructure Initiative on Neutron Scattering and Muon Spectroscopy, NMI3), the second target station at ISIS and the commissioning of the research reactor FRM II in Germany. The future of the European Spallation Source was also a matter of intense discussions. The Commission decided to hold their business meeting in 2004 to proceed further with the preparations for the organization of the Congress in Florence.

The European neutron community will benefit from the support of the European Research Framework Program FP6. In 2003, NMI3 has 
been evaluated in hard competition with infrastructures and projects from other research disciplines such as accelerators, synchrotron sources etc. The successful NMI3 comprehensively integrates all aspects of neutron scattering and muon spectroscopy in Europe. It will be a significant contribution to the science research base in the so-called European Research Area for the next four years, having a long-term impact. In this initiative, 23 partners from 14 countries will collaborate, including 11 research infrastructures and other interested organizations. The effective use and development of the funded research infrastructures are provided by 12 access activities offering approximately 5,000 beam days at about 150 instruments for at least 1,700 users. Furthermore, four networking activities and eight joint research activities on enhanced instrumentation and techniques involving 50 research groups will be partially supported. The total financial volume of NMI3 is about EUR 24M and the direct European funding about EUR 21M, spread over four years.

The impact of ISIS on condensed-matter research using neutron scattering will be strengthened by the construction of the second target station (TS-II). In June 2003, the scientific advisory committee decided on seven priority instruments to be built in the first phase. With the criteria of scientific quality, exploitation of the characteristics of TS-II, user community support and technical challenge and/ or feasibility, it was decided that a cold neutron multi-chopper spectrometer, an off-specular reflectometer, a small-angle neutron scattering instrument and a high-resolution magnetic diffractometer should be first priority and a reflectometer for interfaces, a near- and intermediate-range-order diffractometer and a polarized neutron reflectometer should be second priority.

The FRM II research reactor at Munich, Germany, finally obtained its licence for nuclear start-up and operation from the Nuclear Licensing Authority in May 2003. This licence includes instructions for running the facility and, in addition, the condition to develop a low enriched fuel element. After a general inspection of all reactor components had been carried out, the FRM-II became critical in March 2004 and the first start up to full power will end presumably in mid-2004. The FRM II high neutron flux will offer new possibilities for a broad range of applications for the German and European community; its access will also be supported within the frame of NMI3.

The Japanese project J-PARC is a multi-disciplinary facility including neutron and muon facilities, a nuclear-particle physics facility, a neutrino facility, a $400 \mathrm{MeV}$ proton linac, a $3 \mathrm{Gev}$ synchrotron and a $5 \mathrm{GeV}$ synchrotron, whose construction was initiated in April 2001. The materials life science facility is in charge of the $1 \mathrm{MW}$ pulsed neutron source. At present, procurements of the target installations are almost complete and the construction of the facility building has started. A certain level of funding for the J-PARC neutron beam lines including instrumentation was approved by the Neutron Science Research Center at JAERI for the Japanese Fiscal Year (JFY) 2004. The first beam is expected by the end of 2007. While the ESFRI (European Strategy Forum for Research Infrastructures) stated at the end of 2002, in its strategy paper, that Europe needs a major new spallation source in the long run, the perspective of the ESS (European Spallation Source) still remains uncertain. 2003 and 2004 were and will be used for consultations, evaluations, broadening the science case and obtaining consensus on the scope of the facility. A new web site has been made available to provide information on ESS (http://www.neutron-eu.net). The UK government has committed itself to consultations with its European partners to arrive at a common view on the feasibility and potential of ESS.

M. Steiner, Chair

\subsection{Commission on Powder Diffraction}

4.14.1. Newsletters. The summer issue (No. 29) of the CPD Newsletter was edited by A. N. Fitch and was entitled Powder Diffraction in Action (see also the URL http://www.mpi-stuttgart. mpg.de/cpd). As can be seen from the title, this Newsletter is devoted to the various aspects of in situ powder diffraction. It nicely reflects current achievements in this rapidly growing area and underlines the importance of the CPD Newsletter in reporting recent achievements and trends in powder diffraction. The winter issue (No. 28) edited by C. Hubbard is slightly delayed. Publication is expected shortly after submission of this report.

Started by our previous Chair, P. Scardi, we have now finished the task to transfer all of the older CPD Newsletters from paper to electronic format. All issues of the scanned Newsletters have finally been corrected for scanning and typographical errors and are now available at http://www.mpi-stuttgart.mpg.de/cpd/html/newsletter. html. All Newsletters easily fit on a 'collectors' CD-ROM.

The popularity of the computer software pages by L. M. D. Cranswick is still very high. These pages are very much appreciated by readers for their informative content and their effective presentation. News from ICDD and from IXAS are also present in all issues, together with news on forthcoming events.

I have started to keep our address base up to date by removing false addresses etc. Therefore, since the largest expenses are due to mailing costs, I urge all subscribers to report address changes to me in good time.

4.14.2. Projects. Size-Strain Round Robin. The paper describing the main results of this round robin is in the pipeline. As soon as it is published, it will be included as a supplement to one of the forthcoming Newsletters.

4.14.3. Meetings/workshops/schools. Meetings of interest for the CPD in 2003 included the 21st European Crystallographic Meeting in Durban, South Africa, 24-29 August 2003, where the CPD meeting also took place. The CPD gave support to a Workshop on Radiation Based Analytical Techniques, Cape Town, South Africa, 24-27 October 2003 and to the conference Structure Solution from Powder Diffraction Data, Stara Lesna, Slovakia, 14-19 September 2003. The CPD also supports the next Reynolds cup in quantitative minerals analysis. ICDD and IXAS: As for the previous year, Bob Snyder represented the ICDD at the CPD meetings, and now also the IXAS (information is available via the ICDD web site http://www.icdd.com/ and the IXAS web site http://www.ixas.org/). It is still a main target of the CPD to keep active collaborations and positive relationships with these organizations.

4.14.4. Web site. The CPD web site has undergone a major reorganization. Besides links and information on events related to powder diffraction (including the CPD round robins), the web site gives free access to the CPD Newsletter archive, from which recent and past issues can be downloaded in pdf (Acrobat) format. The CPD tries to increase activity in teaching. In this regard, I would like to draw the attention to our new section for 'educational exercises' and 'teaching pamphlets' at http://www.mpi-stuttgart.mpg.de/cpd/html/ news.html. In particular, the exercise on how to distinguish between the different isomers from Alq3 (a 'hot candidate' for blue LEDs) using high-resolution powder diffraction data is good. The teaching section is still in its infancy and we strongly hope that more people will send in their contributions for the benefit of everyone in the community. In the long term, the CPD will be involved in a project for a basic textbook on powder diffraction which will be published by the Royal Society of Chemistry.

R. E. Dinnebier, Chair 


\subsection{Commission on Small-Angle Scattering}

4.15.1. Commission meetings and communication. As in previous years, various members of the Commission were able to meet in connection with meetings and conferences around the world. These opportunities were important with respect to exchange of ideas and opinions, and to plan the future directions of the Commission's work. However, most of the Commission's communications were by means of e-mail correspondence.

4.15.2. Activities. The main activities that took place in 2003 are:

(1) The Commission (D. I. Svergun and J. S. Pedersen) made a call in 2002 through the SAS list-server for SAS-related links to web pages on hardware and software. The material has been edited by D. I. Svergun and J. S. Pedersen and placed on the Commission's web pages.

(2) The Commission has been discussing an extension to the web page with important references on technical issues such as absolute calibration, $q$ calibration, smearing effects and data analysis. It has also been suggested that more introductory material should be included. Currently, there is a reference/link to an introduction from S. King. The Commission believes that it would be very useful to include lecture notes from some of the many SAS schools that have taken place in the past, and for which there are no copyright problems, so that they could also be put on the web. These lecture notes may be introduced/commented on by a member of the Commission in order to allow a beginner to choose the articles to read according to his/her needs.

(3) The Commission is also considering starting to build an atlas of textbook examples for the interpretation of SAS data. Each example could be a single page with the SAS data set, some explanation of how to interpret it, and with references to the papers where more information can be found. The central point of the example should be the figure with the data set. Such an atlas would be very useful for beginners.

(4) The Commission is considering initiating a round robin with inter-laboratory checks of calibration procedures for SAXS. Although there have been some critical comments on this within the Commission, we will most likely continue our efforts in this direction. It will be a time-consuming effort and the expected outcome might not be too exciting from a scientific point of view, since the most important results will just be given as discrepancies of a certain magnitude between data measured in different laboratories. However, it will provide new insight into the agreement of calibration procedures used in different laboratories. In principle, a procedure based on a sound physical principle should make such a round robin superfluous. However, an empirical verification of the procedures is important in order to demonstrate that the physical principles are being correctly applied in all laboratories within the community, since individual laboratories might introduce biases into every measurement that they make or some factors in a measurement process may be uncontrolled, leading to a lack of repeatability in the results. Suitable samples to be used in a round robin should fulfil the following conditions:

(i) stability in the beam;

(ii) uniformity with respect to composition and preparation;

(iii) simplicity in handling;

(iv) the presence of features;

(v) a well known mechanism for structure generation;

(vi) scattering intensity suitable for laboratory and synchrotron X-ray sources;

(vii) isotropic scattering.
It seems that semi-crystalline samples of polyethylene (PE) samples are the most suitable.

(5) In connection with the Florence Congress, the Commission has suggested four small-angle-scattering-related microsymposia and a one-day tutorial workshop. A. Benedetti, University of Venezia, Italy, has been taking care of the communication with the Congress organizers on behalf of the Commission.

(6) The next International Conference on Small-Angle Scattering, SAS2006, will be held in Japan. T. Hashimoto (University of Kyoto) will chair SAS2006 and discussions on the organization and the programme will start substantially in 2004. Y. Amemiya of the Commission is a member of the Organizing Committee of SAS2006, and will communicate the progress on the organization to the Commission frequently. At this moment, the tentative schedule is as follows: 9-13 July 2006, Kyoto International Conference Center. The first circular is expected around July 2004. Members of the Commission are scheduled to be included in the International Advisory Committee of SAS2006. The Commission will take responsibility for the SAS prizes (administration, funding and support for prizes) at future SAS conferences. G. Kostorz, a consultant of the Commission, will be working for the publication of the Proceedings for SAS2006 in Journal of Applied Crystallography, as for previous Proceedings. This is strongly supported by the Commission. G. Kostorz has also offered his help with editing the Proceedings.

4.15.3. Educational activities. P. Fratzl organized the NESY Winter School for Austrian researchers Forschung mit Neutronen und Synchrotronstrahlung an Europäischen Großforschungsanlagen, Sportheim Planneralm, Steiermark, Austria, 9-15 March 2003. G. Kostorz and J. S. Pedersen lectured at this school.

P. Thiyagarajan presented a lecture entitled 'SANS and SAXS in Structural Biology' at the 5th National School on Neutron and X-ray Scattering, Argonne National Laboratory, USA, 11-23 August 2003. $60 \mathrm{PhD}$ students from US universities attended this annual school. He also offered a tutorial and hands-on training on the SAND instrument for 20 National School students on 'SANS of Block Copolymer Micellar Solutions'.

P. Thiyagarajan presented a talk entitled 'Characterization of Soft Matter of Industrial Importance' by SANS at the Intense Pulsed Neutron 2003 meeting, Tsukuba, Japan, 25-29 October 2003. The objective was community building in Japan.

I. Torriani organized in November 2003 a four-day short course on SAXS theory and applications at the LNLS in Brazil for 25 graduate students, with tutorials on data treatment.

D. I. Svergun presented a lecture entitled 'Synchrotron X-ray and Neutron Small-Angle Scattering for Structure Analysis of Biological Macromolecules' at the Sixth International School on the Crystallography of Biological Macromolecules, Como, Italy, May 2003.

4.15.4. Community building activities. $P$. Thiyagarajan has facilitated SANS experiments at IPNS and SAXS at APS for several groups not familiar with SAS techniques. He further developed a pressure cell with sapphire windows that will allow measurements of SANS up to $200 \mathrm{MPa}$ and a temperature up to $270^{\circ} \mathrm{C}$. It has been used for polymer melts and liquid samples.

P. Thiyagarajan has successfully implemented a GaAs-semiconductor-based beam monitor on the beam stop of a SAND instrument at the IPNS that allows concurrent measurements of both transmission and scattering. He has distributed an analysis package on Igor Pro platform to all the users at IPNS and the users of the SAXS instruments at 18-ID and 12-ID beam lines at APS. This package contains a large number of options to deal with the form 
factors of different morphologies, structure factors, fits to power law, Guinier, Zimm, Porod analysis etc.

D. I. Svergun announced the ATSAS2.0 small-angle scattering analysis program package during 2003 . The package contains a large suite of programs for primary data processing and advanced analysis.

I. Torriani reports from the LBLS in Brazil: In the past two or three years, there has been an increased number of researchers wishing to use scattering techniques, many of them from the biosciences. This includes people not only from Brazil but also from other Latin American countries, such as Mexico, Argentina and Chile, and even from the US (Louisiana State University) and Europe (Italy, Germany, Portugal). As a rule, none of the researchers in Latin America have enough resources or possible grants to mount laboratory SAS facilities, and the solution is to try and obtain beam time at the Brazilian Synchrotron Laboratory (LNLS). In July 2003, the LNLS decided to start the construction of a second SAXS beamline. Improved optics and new instrumentation are the new features. The instrumentation is already being mounted and we expect to start commissioning in July 2004.

At the LNLS in Brazil, successful in situ recordings of SAXSWAXS data from polymer blends have been carried out. This was followed by the installation of a set-up for WAXS-SAXS-DSC at the LNLS, which was completed in 2003 and is now open to the polymerscience community.

A. Allen has been coordinating a NIST Standard Reference Material (SRM) Development Proposal. One needs to determine more precisely the world market for a SAS absolute intensity calibration standard. Such a standard would serve the needs of the SAS community, within both research and industry. It will complement the Commission's planned round-robin activity.

A. Allen and P. Thiyagarajan have been involved in the development of an International Consortium on USAS: in May 2003, a meeting was held at Oak Ridge to discuss the state of Bonse-Hart USANS and USAXS development, given the major advances that are ongoing in both these fields. The Oak Ridge meeting was dominated by USANS. A follow-up, at the 2004 ACA meeting in Chicago, is likely to be stronger in USAXS.

4.15.5. Consultant activities. P. Thiyagarajan and A. Allen have served as reviewers for the small-angle scattering section, three times a year, on the Proposal Review Panel for the Advanced Photon Source, Argonne National Laboratory, USA. P. Thiyagarajan also served on the National Institutes of Health.

A. Allen serves on the SANS Program Advisory Committee (PAC) for the NIST Center for Neutron Research. This panel reviews SANS proposals and allocates all general user SANS beam time. The PAC met twice in 2003 .

D. I. Svergun served as a review panel member for evaluation of the research activity of the Structural Biochemistry Laboratory (RIKEN, Himeji, Japan).

J. S. Pedersen served on the review panel of the EMBL outstation in Hamburg, March 2003.

D. I. Svergun serves as a member of Sub-committee 8 (biology) for proposal selections at ILL (Grenoble, France), twice a year.

J. S. Pedersen is a member of the review panel for beamtime applications within Soft Condensed Matter and Biological Materials at the ESRF, France. There are two proposal rounds per year.

D. I. Svergun and J. S. Pedersen serve as reviewers at the GKSS Neutron Scattering Facility in Germany for proposals submitted through the EU programme ACCESS to Research Infrastructures.

J. S. Pedersen was on the review panel of beamline ID02 at the ESRF in November 2003.
4.15.6. Organizational activities. P. Thiyagarajan organized an International Workshop on Neutron Macromolecular Crystallography at SNS, Argonne National Laboratory, USA, 2-3 October 2003. 60 participants from the USA, Europe and Japan attended.

D. I. Svergun has worked on organizing the EMBO Practical Course on Solution Scattering from Biological Macromolecules, which will take place at EMBL Hamburg Outstation, Germany, 29 October-5 November 2004.

J. S. Pedersen is a member of the Organization Committee of the European School on Scattering Methods Applied to Soft Condensed Matter, Bombannes, Gironde, France, 5-12 June 2004.

4.15.7. Miscellaneous. J. D. Barnes, consultant of the Commission, has been handling the SAS web site. It is comfortably located within IUCr web space. J. D. Barnes would like to hand the task over to the active members of the Commission, preferably before August 2005 so that the new person will have taken over the duties by the time of the Florence Congress.

\section{J. S. Pedersen, Chair}

\subsection{Commission on Structural Chemistry}

The Commission was involved in few activities in 2003 but was asked to nominate members with interests in structural chemistry for inclusion in the Scientific Programme Committee (SPC) for the Florence Congress. L. Brammer (UK) was recommended as a SPC member by the Commission and was subsequently appointed alongside F. Lahoz (Spain), SPC Chair C. Mealli (Italy) and past Chair M. Kaftory (Israel) who also have interests in structural chemistry.

No requests were received during 2003 from organizers of conferences and symposia for Commission support in seeking IUCr funds.

In 2002, a recommendation had been made by the Commission to the Sub-committee on the Union Calendar that it consider reducing from nine months to six months the time in advance of conferences that requests for IUCr financial support need to be submitted. However, this recommendation was not taken up in the new guidelines released in 2003. [Adequate time has to be allowed for subsequent visa applications etc.]

Two meetings organized by Commission members and for which IUCr support had been sought were held in 2003. The 3rd National Russian Crystal Chemistry Conference was held in Moscow, 19-23 May 2003, and funds were committed by the IUCr in support of the meeting. The Programme Chair was Commission member V. Belsky. The Indaba IV meeting, entitled Patterns in Nature, was held in Skukuza in the Kruger National Park, South Africa, 17-22 August 2003 as a satellite of the European Crystallography Meeting in Durban, South Africa. Commission member D. Levendis served on the Organizing Committee, and L. Brammer and G. R. Desiraju served on the Programme Committee. In attendance were 83 people from 15 countries, with 26 young scientists supported by IUCr grants. Commission member D. Braga also organized and served as Chair of a Euro Conference on Molecular Crystal Engineering, held in Maratea, Italy, in June 2003.

\section{Brammer, Chair}

\subsection{Commission on Synchrotron Radiation}

The Commission endorsed conference activities in several scientific areas where SR meets crystallography, sending letters specifically to: 
(i) V. Holy and Z. Sourek of the University of Prague, Czech Republic, who are organizing the next XTOP conference in Prague in September 2004. The programme in its present state of planning looks very interesting and is trying to add some new crystallographic directions to the traditional subject of X-ray topography.

(ii) D. C. Creagh, University of Canberra, Australia, for the International Radiation Physics Society's Triennial Symposium in Cape Town, South Africa, 27-31 October 2003, preceded by a Workshop on Radiation Based Techniques. The latter deals with the interaction of radiation with matter - in particular, synchrotron radiation and neutrons, and the Rietveld technique.

(iii) $\AA$. Kvick of ESRF, Grenoble, France, and N. Greaves of the University of Wales, UK, who are organizing the fourth Conference on Synchrotron Radiation in Materials Science (SRMS-4) in Grenoble, 23-25 August 2004. The conference covers the following subject areas: nanostructures; semiconductors and optoelectronics materials; clusters; micro/mesoporous materials; biomaterials and polymers; magnetic materials; charge, spin and orbital ordering; engineering materials; surfaces and interfaces; ceramics and glasses; and extreme conditions and techniques.

Other activities of the Commission this year were:

(1) Continuation of our efforts to encourage and disseminate information about X-ray detectors.

The Commission sent a letter of support for the proposal of $\mathrm{H}$. Padmore from the Advanced Light Source in Berkeley. The proposal is for construction of a full-scale pixel detector, with every pixel having energy encoding and time stamping. The plan is to make a detector that is fairly 'universal', although the basic framework is quite flexible and will allow many upgrades and customization for specific experiments. It is based on a deeply deplete $(300 \mu \mathrm{m}) \mathrm{Si}$ PIN diode sensor, and therefore this will only give good performance for energies up to around $15 \mathrm{keV}$. For higher energies, it is proposed in parallel to develop a GaAs sensor and to test this at the single chip level, which would give good performance up to $30 \mathrm{keV}$. The options of photon correlation on the chip would be particularly appealing: this is achieved by time stamping each photon it sees with a precision of $10 \mathrm{~ns}$. The time-stamped data are then pipelined to a bank of FPGA processors to calculate the time autocorrelation or cross correlation functions.

Pixel detectors appear to be the best 'new' technology on the horizon for future SR needs. There are several parallel efforts worldwide that would benefit greatly from the communication efforts of the Commission and other bodies. There are technology transfer activities at CERN through the so-called medipix consortium. This aims to develop their existing pixel technology for medical imaging, which is all GaAs based. There are also development efforts at Rutherford Appleton Laboratory (RAL) on some aspects of pixel design, where they have the responsibility to build pixel detector systems for the DIAMOND SR source.

(2) Participation in a SR nomenclature discussion with D. M. Mills of APS and A. Authier on behalf of a Working Group from the Commission on Crystallographic Nomenclature. They have prepared a draft report that will be published in Acta Cryst. Section A and in $J S R$.

The discussion concluded that there was a slight preference for use of the terms 'brightness' or 'spectral brightness' rather than 'brilliance'. They came to the conclusion that 'spectral brightness' is the best term as it specifically shows the importance not only of the number of photons per second per unit source size and unit divergence, but also the number of photons in a particular bandwidth.

I. Robinson, Chair

\subsection{Commission on XAFS}

No report has been received from the Chair.

\section{Arvanitis, Chair}

\section{Sub-committee on the Union Calendar}

The Sub-committee receives and considers requests for IUCr sponsorship and nominal financial support and makes recommendations to the Executive Committee. Acting on the recommendations made by the Sub-committee, during 2003 the Executive Committee approved sponsorship of various schools and meetings, mostly with financial support. Those held in 2003 are listed at the beginning of this Report of the Executive Committee. Those scheduled for 2004, but approved in 2003, are listed below:

Latin-American Course of Macromolecular Crystallography: From Crystal to Structure to Biological Function, Buenos Aires, Argentina, 20 March-2 April 2004.

Second Moroccan School of Crystallography, El Jadida, Morocco, 10-14 May 2004.

School on Diversity Amidst Similarity: A Multidisciplinary Approach to Polymorphs, Solvates and Phase Relationships, Erice, Italy, 9-20 June 2004.

School on Electron Crystallography: Novel Approaches to Structure Determination of Nano-Sized Materials, Erice, Italy, 9-20 June 2004.

AsCA '04, Hong Kong, People's Republic of China, 27-30 June 2004.

XVI International School on Physics and Chemistry of Condensed Matter, Bialowieza, Poland, 1-10 July 2004.

Gordon Conference: Electron Distributions and Chemical Bonding, South Hadley, MA, USA, 4-9 July 2004.

ACA Annual Meeting, Chicago, IL, USA, 17-22 July 2004.

Twelfth International Summer School on Crystal Growth, Berlin, Germany, 1-7 August 2004.

ICCG-14 and ICVGE-12, Grenoble, France, 9-13 August 2004.

International Workshop on Nanomagnetism, Havana, Cuba, 14-18 November 2004.

Organizers of meetings wishing to seek IUCr sponsorship should submit applications at least nine months in advance of the meeting, writing to the Chair of the Sub-committee. The present Chair is Professor M. A. Carrondo. For up-to-date contact information, application procedures and rules, see http://www.iucr.org/iucr-top/ iucr/calendar.html.

Applications for sponsorship of satellite meetings require the approval of the Chair of the Organizing Committee of the main meeting. Meetings (other than satellite meetings) scheduled to be held within two months before or after an IUCr Congress will not be considered for sponsorship. For any meetings scheduled to be held between two and three months before or after a Congress, the application for sponsorship will be sent to the Chair of the Congress Programme Committee for approval, or otherwise. Meetings (other than satellite meetings) scheduled to be held, in the respective region, within two months before or after a meeting of a Regional Associate will not be considered for sponsorship unless the application has received the approval of the Chair of the Programme Conmmittee of the Regional Associate meeting.

The IUCr continues to support and uphold ICSU's policy of nondiscrimination and adheres to its decisions and procedures concerning the free circulation of scientists. Organizers of any meetings seeking IUCr sponsorship or support must assure the Calendar Sub-committee that the authorities of the country in which 
the meeting is to take place guarantee free entrance of bona fide scientists from all countries.

\section{Sub-committee on Electronic Publishing, Dissemination and Storage of Information (CEP)}

\subsection{Meeting attendance}

In 2003, members of the CEP attended the following meetings:

H. D. Flack attended the discussion meeting organized by ICSTI entitled Open Access to Scientific and Technical Information: State of the Art and Future Trends, Paris, France, 23-24 January 2003. H. D. Flack also acted as IUCr representative at the ICSTI winter committee meetings, Paris, France, 25-26 January 2003.

H. D. Flack visited the IUCr editorial offices in Chester, UK, 28-30 April 2003. On this occasion, D. Russon, representing ICSTI, and S. Parsons also visited Chester.

H. D. Flack visited the IUCr editorial offices in Chester, UK, 20-22 October 2003.

H. D. Flack, as special representative of ICSTI, attended the meeting The Role of Science in the Information Society (RSIS), Geneva, Switzerland, 8-9 December 2003; RSIS was a satellite meeting, organized by CERN, to the World Summit on the Information Society organized by the United Nations Organization, Geneva, Switzerland, 10-12 December 2003.

The meeting attendances of the CODATA and ICSTI representatives, whose work is so closely related to that of the CEP, are recorded in their individual reports.

\subsection{Information services}

The CEP has continued its task as editorial body for the on-line information services of the IUCr. The task of day-to-day maintenance of Crystallography Online is performed under the responsibility of S. Parsons. Y. Epelboin continues his good work on the maintenance of the list of software of interest for crystallography. Action has been taken on the restyling and restructuring of Crystallography Online. This activity concerns the functionality, the stylistic attributes and the technical specifications of a revamped IUCr information service. Particular attention was made to the ease of use and integration of the several components of the IUCr information services. Thought was given to the place of the voluntarily maintained mirror sites within the system under development.

\subsection{World Directory of Crystallographers (WDC)}

By way of the online interface of $W D C 11$, entries are gradually being updated by individuals. However, more publicity is necessary to encourage crystallographers to keep their own record up to date.

\subsection{NeXus CD-ROM}

Under the continued leadership of L. M. D. Cranswick, 1,000 copies of a new version of the 'Xtal NeXus: Virtual Crystallographic Internet on CD-ROM' version 8.57 were produced in June 2003 in time to be distributed at the Asian and European Crystallographic Association meetings in Broome, Australia, and Durban, South Africa, respectively. All of these CD-ROMs have now been distributed and, at present, individual CD-ROMs are being made on request. The CD-ROM is made available to laboratories and scientists with an interest in crystallography lacking adequate connection to the internet. The CD-ROMs contain public domain software and copies of web sites of interest to crystallographers. The CD-ROMs were publicized through many channels in such a way that scientists have to apply to receive a copy. We propose to continue this project and to make and distribute further batches of CD-ROMs. L. M. D. Cranswick's move of location from England to Canada should not impede the continuity of this project.

\subsection{Crystallography Journals Online and open access}

Attention continues to be given to ways of improving the sale of the IUCr journals to consortia of libraries. Moreover, the CEP is particularly attentive to developments in the scientific community at large concerned with access to scientific literature and data. The CEP devoted considerable time and effort in the management of openaccess initiatives related to crystallographic publications and data. This activity resulted in the production of position papers on open access for consideration by the Executive Committee, whose decisions on these matters are reported elsewhere.

\subsection{International Tables for Crystallography}

Very close to the end of 2003, activity was commenced around the specification of new business and functional models for electronic versions of the information contained in International Tables for Crystallography.

\section{H. D. Flack, Chair}

\section{Committee for the Maintenance of the Crystallographic Information File Standard (COMCIFS)}

COMCIFS is charged with the supervision of the Union's Crystallographic Information File (CIF) project. The current members of COMCIFS are: I. D. Brown (Chair), H. M. Berman, H. J. Bernstein, R. W. Grosse-Kunstleve, S. R. Hall, G. Madariaga, B. McMahon and J. Westbrook. Except for meetings held during the IUCr General Assemblies, COMCIFS conducts all its business by email.

This year saw the deadline for receipt of text for the forthcoming Volume $\mathrm{G}$ of International Tables for Crystallography, a volume dedicated to giving a full description of the history, philosophy and technical details of CIF, its dictionaries and applications. Publication of this volume is expected in 2005 under the editorship of S. R. Hall and B. McMahon. In order to ensure that the volume is as current as possible, COMCIFS this year approved several new and revised dictionaries.

One approval was a revision of the image CIF dictionary (cif_img_1.3.1), which includes a number of minor modifications that were found necessary when writing software to read and write imgCIFs. At the same time, a new version of CBFlib was released by H. J. Bernstein and P. Ellis.

The core CIF dictionary has been in use for over a decade for submitting small-cell crystal structures for publication in the Union and other journals. A major revision was therefore due and it is being undertaken in two stages. The first, which was approved during the year as version cif_core_2.3, includes a number of new items requested by the IUCr and the Cambridge Crystallographic Data Centre as well as the replacement of the symmetry category by items from the space_group category of the recently approved symmetry CIF dictionary.

The Core Dictionary Maintenance Group is continuing with the second part of the revision, which will include additional items for reporting twinning, and for complementing the crystallographic description of a compound with a chemical description. Users will be able to identify the molecules present in the crystal and list their chemical properties. Cif_core_2.4 is expected to be ready for COMCIFS approval during the coming year. 
COMCIFS also approved a new dictionary for reporting electron densities (cif_rho_1.0). Following our usual practice, this was accompanied by the appointment of a Dictionary Maintenance Group whose members, drawn from the electron density community, are: P. Mallinson (Chair), L. Farrugia, N. Hansen, C. Jelsch, T. Koritsanszky, P. Macchi, H. O. Sørensen and A. Volkov.

Two much needed CIF editors and browsers were released during the year. The long awaited enCIFer [F. H. Allen, O. Johnson, G. P. Shields, B. R. Smith \& M. Towler (2004). J. Appl. Cryst. 37, 335-338; http://www.ccdc.cam.ac.uk/free_services/encifer/], produced by the Cambridge Crystallographic Data Centre, is designed to assist authors in preparing CIFs for submission to the Centre, but it may be used by anyone wishing to create or check a CIF. CIFEDIT [B. H. Toby (2003). J. Appl. Cryst. 36, 1288-1289] is an editor developed in connection with a powder diffraction package. The two editors operate in different ways but both provide direct access to the definitions in the CIF dictionaries selected by the user, thus ensuring that the CIF output from the editor conforms to the definitions in the dictionary.

A new version of Rasmol has been released, which will display RCSB Protein Data Bank mmCIFs in the same way as it currently displays pdb2cif mmCIFs.

I. D. Brown, Chair

\section{Committee on Crystallographic Databases}

Developments in all of the crystallographic databases have continued unabated during 2003. By the end of the year, the structural databases (PDB, NDB, CSD, ICSD, CRYSTMET) contained details of nearly half a million crystal structures, with an overall accession rate of about 37,500 new structures predicted for 2004. The PDB, in particular, shows a very rapid growth rate, which is being ably assimilated under RCSB management. In 2003, the CCDC released Version 1.0 of the enCIFer program for CIF validation and editing, which is available for free download from their web site for bona fide research use. The ICDD have released PDF-4/Organics, a set of powder patterns calculated from the contents of the Cambridge Structural Database.

Members of the Committee have expressed their views of the proposed Crystallography Open Database to the IUCr Executive Committee and further discussions will be ongoing into 2004 .

\section{F. H. Allen, Chair}

\section{IUCr Newsletter}

Five issues of the IUCr Newsletter were produced in 2003. One contained 24 pages and the others 32 pages. The fifth issue was mailed out in early 2004. As in previous years, the content covered activities of the IUCr and its Regional Associates, news concerning crystallographers and crystallography, notices, awards, elections, resources, obituaries, meeting reports, future meeting announcements, and a general meeting calendar.

Each issue devoted two or three pages to brief summaries of selected articles recently published in IUCr journals.

Session reports from the Geneva Congress were featured in three of the five issues. Twenty two other meeting reports, including ECM21 in South Africa, were covered. The meetings were held in 15 different countries. One issue (Volume 11, No. 3) highlighted crystallography in Latin America with special emphasis on crystal- lography in Brazil. Twenty five future meetings, in 14 different countries, were announced. One issue (Volume 11, No. 4) contained the call for papers for ECM-22. Announcements for the Florence Congress were also featured. We published excerpts from the final report of the Inter-Union Bioinformatics Group and an announcement of the formation of the Worldwide PDB. Volume 11 contained another update on CIF dictionaries and on the progress of preparation of Volume G of International Tables for Crystallography. Prizes were announced, as were calls for nominations for the ECA and Ewald prizes. Nine obituaries were published, representing four countries.

Each issue started with the IUCr President's column and three issues had guest editorials by J. R. Helliwell, M. G. Rossmann and C. Mealli.

The mailing list was larger than it was in 2002. Nineteen countries (up from 18 in 2002) now assist in the effective and economic distribution of the Newsletter. There are 26 countries that currently receive fewer than five copies of the Newsletter. These countries were listed in issue Volume 11, No. 4 in hopes that more crystallographers in those countries would provide information to the World Directory of Crystallographers and thereby be added to the Newsletter mailing list. Sustained advertising volume coupled with efficient production kept the cost to the IUCr below USD 25,000 for the year. (Distributors: B. W. Skelton, Australia; J. Valderrama-N., Colombia; B. KojicProdic, Croatia; A. Gomez, Cuba; J. Hasek, Czech Republic; C. Lecomte, France; Executive Secretary and A. Nangia, India; P. Spadon, Italy; A. Satomi, Japan; A. H. Othman, Malaysia; Honorary General Secretary, New Zealand; J. Lipkowski, Poland; M. Costa, Portugal; L. Nassimbeni, South Africa; H. Grimmer, Switzerland; Yu Wang, Taiwan; K. Haller, Thailand; R. Olthof-Hazekamp, The Netherlands; G. Diaz De Delgado, Venezuela.)

\section{J. L. Flippen-Anderson, Editor}

\section{IUCr/Oxford University Press (OUP) Book Series}

The Book Series Committee continued its activities during 2003. In the series IUCr Monographs on Crystallography, the book Dynamical Theory of X-ray Diffraction by A. Authier was published in November. Three books are under consideration or in the production phase.

Prospective authors are encouraged to contact the Chair of the Committee (schenk@science.uva.nl). Manuscripts covering specific aspects of crystallography and related fields are most welcome.

H. Schenk, Chair of Book Series Committee

\section{Regional Associates and Scientific Associates}

\subsection{American Crystallographic Association (ACA)}

The activities of the ACA during 2003 were well in line with its major objectives regarding scientific and educational programmes, which included the continued support to young scientists and students from the USA and abroad. The publication of the $A C A$ Newsletter continues to be a very successful way of reaching the crystallographic community.

In 2003, two Summer Courses were organized before and after the ACA Annual Meeting. The first, on Macromolecular Crystallography, took place at the Illinois Institute of Technology (12-26 July 2003) and the second, on Small Molecule Crystallography, at the Indiana University of Pennsylvania (3-13 August 2003). Visa problems for 
foreign students were a major worry for the organizers, who, together with the US National Committee for Crystallography, have taken steps to help and advise the applicants of forthcoming schools.

The 2003 ACA Annual Meeting was held in Covington, Kentucky, USA, 26-31 July 2003, with the participation of more than 900 crystallographers. As part of a well balanced and high level scientific programme, several workshops and microsymposia were organized. In particular, special symposia were dedicated to the major ACA awards granted in 2003. The B. A. Warren Diffraction Physics Award was presented to T. Egami, who opened the symposium with a lecture entitled 'Democracy in the Imperfect World: Local Crystallography of Crystals with Disorder'. The Martin J. Buerger Award was granted to J. A. Ibers, whose lecture on hard to solve structures entitled 'Less Difficult but Still not Easy', opened the session. The M. C. Etter Early Career Award was presented to J. Chan (first recipient), who lectured on the structure-property relationships of superconducting and heavy Fermion intermetallics. Five students chosen by the Special Interest Groups received the Etter Student Lecturer Awards. Poster sessions had more than 230 presentations. The Pauling Poster Prize was awarded to five participants and the Oxford Cryosystems Prize was offered to the best work on low-temperature crystallography. In all, a very successful meeting. Future meetings will take place in Chicago, Illinois (17-22 July 2004) and Orlando, Florida (28 May2 June 2005).

In support of Latin-American regional meetings, prizes were offered by the ACA to participants in the International School on Crystal Growth Applications and Characterization that took place in Uruguay in December 2003. Two one-year memberships were granted to young scientists and copies of the Proceedings of the ACA were presented for best poster presentations. A new development regarding the Latin-American initiative is the proposal of allowing any National Crystallographic Association that has at least 20 members and regularly elected officers to apply for Affiliate Membership of the ACA. This proposal was approved by the ACA Council Meeting in October 2003.

\section{L. Torriani, IUCr Representative}

\subsection{Asian Crystallographic Association (AsCA)}

AsCA'03/Crystal-23. As reported last year, some changes have been made in the Association. One change was the introduction of additional AsCA meetings beyond the regular AsCA meeting every three years. The first such meeting, AsCA '03/Crystal-23, was held at Broome, Australia, in August 2003 as a joint conference of AsCA and the Society of Crystallographers in Australia and New Zealand (SCANZ). Broome is situated on the northwestern coast of the continent; the conference site was Cable Beach where the weather was perfect with an average temperature of $25-28^{\circ} \mathrm{C}$. The arrangement of running three conferences back to back at the same place was a great idea; AsCA'03/Crystal-23 was held 10-13 August, a biological workshop followed on 13-15 August, and Sagamore XIV was held 15-18 August. The scientific programme of AsCA'03/Crystal-23 consisted of 6 plenary lectures, 12 microsymposia and 136 posters. Lunches were served in the restaurant at the conference site. A sunset dinner was served on the beach with participants of all three conferences. There were many poster awards given during the conference; an additional award from the IUCr was inaugurated at this meeting and was presented by the IUCr President; the award consists of free individual online access to all IUCr journals for two years.

Planning for AsCA '04. A council meeting was held on 12 August 2003; much of the time was devoted to discussing details of the planning for the AsCA '04 meeting to be held in Hong Kong at the Hong Kong University of Science and Technology. M. Sakata, Chair of the International Programme Committee (IPC), and I. D. Williams, Chair of the Organizing Committee (IOC), gave brief presentations for the planning of AsCA '04. The meeting time and the format of the scientific programmes and a few important dates were decided. Yu Wang, the President of AsCA, and M. Sakata made a visit to the conference venue and had a good discussion with I. D. Williams on 17-18 December 2003.

Locations of future AsCA meeting. AsCA '06 is scheduled to be a joint conference with the Japanese Crystallographic Society (CrSJ). The exact location has not been decided. There will be discussion concerning the site for AsCA '07 at the next council meeting during AsCA '04 (possibilities include Taiwan, Korea and Vietnam).

Y. Ohashi, IUCr Representative

\subsection{European Crystallographic Association (ECA)}

In 2003, the most important activity was the 21st European Crystallographic Meeting, ECM-21, held in Durban, South Africa, 24-29 August 2003, with J. C. A. Boeyens as Chair of the Programme Committee and A. Roodt as Chair of the Local Organizing Committee. The programme included 8 plenary lectures, 45 parallel oral sessions and two poster sessions. Despite the difficulties caused by the revaluation of the Rand over the Euro and the US dollar by some $20 \%$, almost 550 people, from 49 countries, attended the meeting. Approximately 100 students and younger scientists were able to attend as a result of sponsorships, particularly from the IUCr, the ECA and South African institutions. The congress was preceded by the Indaba IV workshop on Patterns in Nature, held at Skukuza in the unique atmosphere of the Kruger National Park, 17-22 August 2003, and by the African Neutron Diffraction Meeting at Amanzingwe, near Pretoria, 21-22 August 2003.

The ECA Council and Executive Committee met in Durban and several important decisions were taken. The importance of holding ECM-21 in South Africa, as a way of collecting all crystallographic activities in Africa and expanding both ECA and IUCr memberships, was recognized, with special thanks to the organizers for their efforts in presenting a well planned meeting. The new SIG on Molecular Structures and Chemical Properties was approved. The new Executive Committee was elected with H. Fuess as President, M. Jaskolski as Vice-President and A. Liljas, A. Roodt and C. C. Wilson as members, while G. Filippini and T. Duarte were confirmed as Secretary and Treasurer and C. Lecomte remained as Past President. L. Fábián gave a detailed description of the arrangements for ECM22 to be held in Budapest, Hungary, 26-30 August 2004. Preliminary steps for the organization of ECM-23 in August 2006 in Leuven, Belgium, were discussed with L. Van Meervelt. The site for ECM-24 in 2007 was chosen to be Marrakesh, Morocco.

The Third ECA Prize was conferred in Durban on C. Giacovazzo for his major theoretical and practical contributions to the solution of the phase problem in a wide spectrum of applications. After the meeting in Durban, the two main activities were: (i) preparation and promotion of the announcement of the Fourth ECA Prize, to be presented in Budapest; (ii) setting up of the Organizing and Programme Committees for ECM-22, chaired by A. Kálmán, and all the initial steps necessary for the organization of a successful meeting. 16 Keynote Lectures and 40 Microsymposia are foreseen in the programme.

D. Viterbo, IUCr Representative 


\subsection{International Organization of Crystal Growth (IOCG)}

During 2003, the IOCG focused its activity on the organization of the triennial congress that will take place in Grenoble, France, 9-13 August 2004 (http://iccg14.inpg.fr) and the triennial Summer School on Crystal Growth that will be held in Berlin, Germany, 1-7 August 2004 (http://isscg12.ikz-berlin.de/index.phtml). Several members and consultants of the IUCr Commission on Crystal Growth and Characterization of Materials are involved in both events as session Chairs, members of the Advisory/Programme Committee or lecturers at the school.

The Executive Committee of IOCG has worked in recent months to improve the visibility of this Organization among the community of crystal growers. First of all, a new web site has been opened (http:// www.iocg.org/), which provides useful information about the organization, its officers and its history as well a number of useful links to national crystal growth organizations. Furthermore, during the conference in Grenoble, a contest will be launched for the creation of a new logo.

Finally, in addition to the traditional Frank and Laudise Prizes, a new prize has been established with the purpose of recognizing a young author for his or her outstanding scientific publications in the field of crystal growth. The prize consists of travel and accommodation expenses (to a maximum of USD 5,000) to the ICCG conference and a certificate citing the contributions made by the recipient. The prize will be awarded every three years during the ICCG conference. The prize will commence in 2004 and is sponsored in full by the Journal of Crystal Growth.

R. Fornari, IUCr Representative

\subsection{International Centre for Diffraction Data}

As for the previous year, R. L. Snyder represented the ICDD at the CPD meetings, and now also the IXAS (information is available via the ICDD web site at http://www.icdd.com/ and the IXAS web site at http://www.ixas.org/).

\section{R. E. Dinnebier, IUCr Representative}

\section{Representatives on Other Bodies}

12.1. IUPAC Interdivisional Committee on Terminology, Nomenclature and Symbols (ICTNS)

The activity level of ICTNS increased in 2003 as its biennial meeting drew near, although the number of IUPAC Technical Reports received and reviewed was smaller than usual. Members welcomed their new Chair, J. W. Lorimer, and recently appointed Secretary, B. J. Herold, at the biennial meeting in Ottawa, Canada, August 2003. Membership includes the former Chair (T. Cvitas) and former Secretary (W. V. Metanomski) as core titular members in addition to two core associate members, one member nominated by each of IUPAC's eight divisions and the representative of each of seven international organizations including the IUCr. Draft minutes of the Ottawa meeting, expected to be circulated within a few months accompanied by copies of all written or verbal reports presented, are still awaited. Minutes of the IUPAC Bureau meeting in Ottawa are available at: http://www.iupac.org/news/index.html.

Among the matters of interest to the IUCr discussed in Ottawa is IUPAC's Chemical Identifier (IChI) project, which is to develop a program establishing a digital signature for each given compound derived algorithmically from its digital structure representation. The first version included covalently bonded structures, with options to specify tautomers, stereochemistry and isotopic substitution. The second version extended the range of applicability to inorganic and organometallic structures. Several principal developers of IChI were present at the meeting. Recognition of the common interest of IChI and the IUCr Working Group on Phase Identifiers led to the participation of I. D. Brown, Working Group Chair, in a meeting at NIST late last year to review the results of testing this version. Several IUPAC progress reports on IChI are available, including http:// www.iupac.org/symposia/conferences/CIandXML_jul02/ program.html\#Stein1.

Related progress by IUPAC's Committee on Printed and Electronic Publications in translating existing IUPAC standard terminologies and related information into data dictionaries was summarized and a need identified for standard XML data dictionaries covering all aspects of chemical techniques; a multiplicity of approaches now exists.

Revisions to the guidelines for drafting IUPAC Technical Reports and recommendations that will appear in the IUPAC Handbook 2004-2005 were completed late last year and early this year.

The Comité Consultatif des Unités (CCU) decided at its last meeting to introduce the Dalton, symbol Da, into Table 7 of the brochure on The International System of Units in the next (8th) edition, due 2004/2005, according it equal status with the unified atomic mass unit (where 'unified' refers to the agreement between physicists and chemists to change the previous definition to $m\left({ }^{12} \mathrm{C} / 12\right)$.

The rules for printing numbers were clarified by the recent resolution of the Conférence Générale des Poids et Mesures that the decimal marker shall be either a comma on the line or a point (i.e. a dot) on the line.

The next meeting of ICTNS is scheduled during IUPAC's 43rd General Assembly in Beijing, People's Republic of China, 2005.

S. C. Abrahams, IUCr Representative

\subsection{International Council for Scientific and Technical Information (ICSTI)}

The ICSTI General Assembly was held in Ottawa, Canada, 8-12 May 2003, at the invitation of the Canada Institute for Scientific and Technical Information (CISTI). This included a one-day public conference entitled Socio-Economic Impacts of Scientific and Technical Information within National Innovation Systems. Unfortunately, it was not possible for the undersigned to attend this meeting. However, the IUCr was represented/will be represented by H. D. Flack at the following ICSTI meetings:

Winter committee meeting and discussion meeting on Open Access to Scientific and Technical Information: State of the Art and Future Trends, Paris, France, 23-26 February 2003.

Winter committee meeting and discussion meeting on Economic Models for Scientific Information, Production and Distribution, Paris, France, 15-18 January 2004.

At the winter 2003 meeting of ICSTI, it was suggested that the IUCr might undertake a survey in conjunction with ICSTI to determine the extent to which policies and practices are in place to ensure the long-term availability of digital publications and data in the field of crystallography.

In May 2003, the IUCr agreed in principle to undertake the survey and it was recognized that there should be two separate survey questionnaires: (a) for individuals who publish crystallographic information and $(b)$ for organizations that publish crystallographic information. Initial drafts of survey questionnaires were discussed at 
international union of crystallography

a second meeting held in August 2003. Subsequent to this meeting, the questionnaires were further refined and comments sought from a number of crystallographers. This led to final drafts of the questionnaires in November 2003. The final drafts were then tested by a number of volunteers.

Online versions of the questionnaires were developed during December 2003, and are available from the web address http:// www.iucr.org/iucr-top/docs/dpsurvey.html. It is expected that the results of the survey will be compiled and made available before the end of 2004.

ICSTI maintains a public web site at http://www.icsti.org/, where the newsletter ICSTI Forum and other general information is made available. A private section is available only to members, the IUCr Representative sharing this opportunity with the IUCr's SubCommittee on Electronic Publishing, Dissemination and Storage of Information (CEP). A distribution list operates where the ICSTI Executive Director distributes news clips and other information. In 2004, the ICSTI annual meeting will take place in London, UK, 13-17 May, organized and sponsored by IEE/INSPEC. The meeting will include a one-day public conference entitled Technical and Economic Challenges of Scientific Information: STM Content Access, Linking and Archiving. In 2005, the winter meeting will probably take place in Paris, France, and the annual meeting in Moscow, Russia. ICSTI is composed of a large spectrum of professionals from the STM and library sectors but with few scientists present. IUCr membership of ICSTI continues to fulfil its expectations by providing a source of current documentation and personal contacts in the field of scientific and technical information (electronic publishing).

P. R. Strickland, IUCr Representative

\subsection{International Council for Science (ICSU)}

At the ICSU General Assembly held in 2002 in Rio de Janeiro, Brazil, the strategy for the triennium had been set out. As a result, ICSU, its officers, its members and its office, led by Executive Director T. Rosswall, will try to represent the voice of science more prominently than before in the world as a whole.

ICSU is setting up Regional Offices as decided in Rio de Janeiro. It is expected that these will initiate the priority areas of ICSU, such as Capacity Building, and will eventually lead to a better distribution of knowledge. Much emphasis was given to the priority area of Scientific Data and Information in order to give significant input to the World Summit on the Information Society, which was held in December in Geneva, Switzerland. Officers of ICSU wrote editorials for the journal Science, ICSU brought out brochures entitled Optimizing Knowledge in the Information Society and Science in the Information Society, and ICSU played roles in sessions and workshops at the World Summit.

Other activities of interest relate to: New Genetics, Food and Agriculture: Scientific Discoveries - Societal Dilemmas; the Environment and its Relation to Sustainable Development; Capacity Building; Energy in Relation to Sustainable Societies; the International Polar Year; International Perspective on National Foresight Studies; Rights and Responsibilities of Science and Society; the United Nations Forum on Forests. As ICSU feels that it should have strong links to the Scientific Unions, a meeting of all the Scientific Union Presidents with the ICSU officers is planned for February 2004.

The ICSU website (http://www.icsu.org) was significantly improved in 2003 and will serve as an important source of information - thus, more information about the above topics, and much more, may be found there.

\section{H. Schenk, IUCr Representative}

12.4. ICSU Programme on Capacity Building in Science (PCBS)

No report has been received.

R. B. Neder, IUCr Representative

\subsection{ICSU Committee on Data for Science and Technology (CODATA)}

CODATA hosted or sponsored the following meetings during 2003:

International Symposium on Open Access and Public Domain in Digital Data and Information for Science at UNESCO Headquarters, Paris, France, 10-11 March 2003. The focus of this meeting, attended by some 150 delegates, was the role, value and limits of public domain and open access to scientific and technological data on a global basis, with particular attention to the needs of developing countries.

International Symposium on e-Drug Discovery, Seoul, South Korea, 20-23 May 2003. This meeting was jointly organized by the Bioinformatics and Molecular Design Technology Innovation Center and the CODATA Task Group on Data Sources in Asian and Oceanic Countries, and explored cheminformatics, virtual screening, ADME/ tox and the Physiome Project in the context of in silico drug discovery.

Access to Data Seminar, NRC, Canada, 26 May 2003, to explore the status of Canadian efforts in ensuring the accessibility of publicly funded natural sciences research data.

EuroCris Seminar entitled Transforming Research Information into Knowledge, Brussels, Belgium, September 2003, discussing current research information systems supporting the European Research Area.

Third International Symposium on Digital Earth, Brno, Czech Republic, 21-25 September 2003. Several sessions and seminars covered topics such as global sustainability, data standards and interoperability in the earth sciences, visualization, data and information infrastructure, and sociopolitical implications of digital knowledge driven communities.

CODATA-ERPANET Archiving Workshop, Lisbon, Portugal, 15-17 December 2003. The major aim of this workshop was to provide an international forum to exchange information about data archiving policies and practices; the meeting attracted 65 participants from 13 countries.

World Summit on the Information Society, Geneva, Switzerland, 10-12 December 2003 (http://www.itu.int/wsis/). This was the first part of a major international summit, in preparation for which CODATA had collaborated with ICSU through 2003 by organizing an online discussion forum hosted on the ICSU website (10-12 March 2003) and an invitation-only workshop (Paris, France, 12 March 2003). An outcome of this workshop was an Agenda for Action circulated for comment and consideration to members and partners. CODATA was involved in the preparatory meeting Prepcom III. CODATA was a coorganizer of a major scientific conference on the Role of Science in the Information Society immediately preceding the Summit (CERN, Switzerland, 8-9 December 2003), and was represented by its President, S. Iwata, at a high-level round table discussion organized by UNESCO on Science, Information Society and the Millennium Goals during the Summit meeting. The Second Phase of the Summit will take place in Tunis, Tunisia, in November 2005. 
There were also a number of Workshops and small-scale meetings held to further the scientific programmes of CODATA Task Groups, namely:

- Task Group meeting on Natural Gas Hydrates (Paris, France, April 2003);

- North American Regional Meeting of Task Group on Natural Gas Hydrates (Salt Lake City, USA, May 2003);

- Species 2000 team meeting (Reading, UK, May 2003) and the GBIF Governing Body meeting (Copenhagen, Denmark, May 2003);

- Fundamental Constants Task Group meeting (Paris, France, July 2003).

The Fundamental Constants Task Group has published a new set of values of physical constants based on data available to the end of 2002 or early 2003. The new values are available from the NIST web site at http://www.physics.nist.gov/constants.

It will be seen that CODATA remains concerned about the largescale and international policy aspects of data access and preservation, and is an energetic and vocal mouthpiece for the scientific community in defence of maximizing access to scientific data.

The publications programme of CODATA has continued through publication of a book of thermodynamic data for multicomponent oxide systems, and through the peer-reviewed online publication Data Science Journal (http://www.datasciencejournal.org/).

The CODATA web site (http://www.codata.org) was radically overhauled in 2003 and offers an excellent gateway to the activities, policies and publications of the organization.

\section{B. McMahon, IUCr Representative}

\subsection{ICSU Committee on Space Research (COSPAR)}

The 65th COSPAR Bureau meeting was held in Paris, France, 20 March 2003. There were several meetings and workshops co-sponsored by COSPAR but none of them were related to subjects close to crystallography and crystal growth.

The day before the Bureau meeting, a new COSPAR Publications Committee was appointed for 2002-2006, comprised of W. Hermsen (Chair), R.-M. Bonnet (ex officio), G. Haerendel (ex officio), R. A. Harrison (ex officio), M. A. Shea (ex officio), D. Halpern, Y. Kamide, F. Raulin, C. T. Russell, K.-P. Wenzel and A. P. Willmore. They will try to increase the impact and the speed of publication of Advances in Space Research, the main journal supported by COSPAR. The Publications Committee enthusiastically endorsed the proposal for typesetting from Elsevier. It was also agreed to change the format of the COSPAR Information Bulletin.

The COSPAR Programme Committee will hold its next meeting 30-31 March 2004. The Bureau decided, therefore, to meet next on 1 April 2004. The Publications Committee will meet on the afternoon of 29 March 2004. All meetings will take place in Paris, France.

The 35th COSPAR Scientific Assembly will take place on 18 July 2004. This one-week conference is full of events that are listed on the COSPAR web site at http://www.cospar2004.org. The scientific Commission on Materials Science in Space is chaired by $\mathrm{R}$. Narayanan, A. Cröll and H. Kawamura. Only one session will be devoted to materials science while life origins, extraterrestrial life and, obviously, space exploration are much more represented.

The 36th COSPAR Scientific Assembly will be held in Beijing, People's Republic of China, while Canada has issued an invitation to organize COSPAR 2008. Italy has also issued an informal invitation to COSPAR for the same year or 2010.

J. M. Garcia-Ruiz and R. Delhez, IUCr Representatives

\section{Finances}

The audited accounts of the year 2003 are given at the end of this Report. For comparison, the figures for 2002 are provided in italics. The accounts are presented in CHF.

The UNESCO rates of exchange, as issued by the ICSU Secretariat, have been used in the preparation of these accounts. As a consequence of the many fluctuations in exchange rates during the year, the following procedure has been adopted for the accounts. Assets and liabilities in currencies other than CHF at 31 December 2003 have been translated into CHF in the balance sheet at the rate operative at that date. For the income and expenditure accounts, transactions have been translated into CHF by applying the rates appropriate to the individual dates of these transactions. As a consequence of the fluctuation in exchange rates, an apparent loss has arisen on the assets of the Union, in terms of CHF, amounting to CHF 290,613. The loss attributable to investment activities has been assigned to the General Fund and the loss attributable to trading activities has been divided amongst the fund accounts in direct proportion to the balances on these accounts at 31 December 2003. It should be noted that this loss in CHF is not a real loss of money, but rather a loss on paper resulting from the accounts being expressed in CHF.

Investments are noted in the balance sheet at their market value at 31 December 2003.

The balance sheet shows that the assets of the Union, including the loss of CHF 290,613 resulting from fluctuations in rates of exchange, have decreased during the year, from $\mathrm{CHF} 4,483,185$ to CHF 4,402,667. The movement in market value of the investments was CHF 272,966 in 2003 (CHF -751,472 in 2002).

A transfer of CHF 20,000 was made to the Book Fund from the Acta Crystallographica Fund. A transfer of CHF 250,000 was made to the Publication and Journals Development Fund from the Acta Crystallographica Fund. A transfer of CHF 140,000 was made to the Research and Education Fund from the Acta Crystallographica Fund. A transfer of CHF 25,000 was made to the President's Fund from the Acta Crystallographica Fund. A transfer of CHF 30,000 was made to the Journal of Synchrotron Radiation Fund from the Acta Crystallographica Fund. A transfer of CHF 45,000 was made to the Newsletter Fund from the Journal of Applied Crystallography Fund. A transfer of CHF 25,000 was made to the Ewald Fund from the Journal of Applied Crystallography Fund.

Beneath the detailed figures of the expenditure and income for each fund account, the balance at 1 January, transfers to and from other funds, the difference between income and expenditure for the year and the fluctuations in rates of exchange during the year are given, showing how the balance at 31 December is obtained. Note that for the General Fund there is an additional entry for 'Movement in market value of investments in the year'.

The General Fund account shows a deficit of CHF 105,661, as compared with a deficit in 2002 of CHF 401,439. The administrative expenses were CHF 449,259 in 2002 as compared with CHF 472,764 in 2002. Of this amount, CHF 197,533 was charged to the publications of the Union.

The expenses of the Union Representatives on other bodies were CHF 4,323. The cost of the Finance Committee meeting held in 2003 was CHF 11,761, while the Executive Committee meeting cost CHF 54,125. The income from the IUCr/Fachinformationszentrum agreement (to provide low-cost copies of the Inorganic Crystal Structure Database) was CHF 13,609. The subscriptions from Adhering Bodies were CHF 148,215. Interest on bank accounts and investments credited to the General Fund was CHF 14,275. 
The President's Fund, the Publication and Journals Development Fund, the Research and Education Fund and the Ewald Fund received interest, at a nominal rate of $2.5 \%$ per annum, on the balances in the funds.

The President's Fund therefore received interest of CHF 1,717. No grants were paid from the fund in 2003.

The Acta Crystallographica account for 2003 shows a surplus of CHF 199,677 before the transfer of CHF 465,000 to other fund accounts, as compared with a surplus of CHF 577,436 in 2002 before transfers of CHF 625,000 . The smaller surplus in 2003 is accounted for by the bankruptcy of one of the main subscription agents; this affected all journal publishers.

The subscription rates were increased for 2003. In 2003, the number of paid subscriptions to Sections $A+B+C+D$ of Acta, including 27 (33) personal subscriptions, was 460 (468) (values for 2002 are given in parentheses). The number of paid subscriptions to Sections $A+B+C$, including 13 (16) personal subscriptions, was 130 (130). The number of paid subscriptions to the separate sections of the journal were: Section A 201 (221 for 2002), Section B 154 (170), Section C 122 (136) and Section D 269 (256). The cost of the technical editing office has been divided between the Acta Crystallographica, the Journal of Applied Crystallography, the Journal of Synchrotron Radiation, the International Tables and the Book Fund accounts in percentages based on the staff time spent on each publication. The technical editing costs (comprising salaries and expenses, computer expenses and depreciation of office equipment) for Acta Crystallographica were CHF 1,113,729 (for 8,735 published pages) as compared with CHF 1,092,762 in 2002 (7,905 pages published). The journal's accounts have also been charged with administration expenses as in previous years as shown in the General Fund.

The Journal of Applied Crystallography account shows a surplus of CHF 98,138, as compared with a surplus of CHF 152,190 in 2002. In 2003, the number of paid subscriptions, including 92 (113 in 2002) personal subscriptions, was 652 (696 in 2002).

The Journal of Synchrotron Radiation account shows a deficit of CHF 40,179 before receiving a transfer of CHF 30,000 from the Acta Crystallographica Fund, as compared with a deficit of CHF 27,235 in 2002 before receiving a transfer of CHF 50,000. In 2003, the number of paid subscriptions, including 70 (90 in 2002) personal subscriptions, was 231 (243 in 2002).

The International Tables account shows a surplus of CHF 80,060, as compared with a deficit of CHF 22,445 in 2002. The net sales income was CHF 221,331 in 2003 as compared with CHF 355,715 in 2002. The high sales income in 2002 was a result of the publication of Volume A that had been out of print for some time and had accumulated significant orders.

The Book Fund is credited with the sales of the remaining publications of the Union. The deficit of CHF 27,988 is attributable to the programming time involved in the restructuring and updating of the World Database of Crystallographers, which is used to produce the World Directory of Crystallographers.

The Newsletter Fund account received a transfer of CHF 45,000 from the Journal of Applied Crystallography Fund in 2003 (CHF 25,000 from the Acta Crystallographica Fund and CHF 25,000 from the Journal of Applied Crystallography Fund in 2002). The cost to the Union of producing the Newsletter in 2003 was CHF 29,165 (CHF 87,795 in 2002). The difference is accounted for by the fact that advertising revenue for five issues was received in 2003, compared with income for three issues in 2002.

As mentioned earlier, the income for the President's Fund account, the Publications and Journals Development Fund account, the Research and Education Fund account and the Ewald Fund account includes interest as well as transfers from other fund accounts. In the Publications and Journals Development Fund account, the computing and promotion expenses are divided between the General Fund, the Acta Crystallographica Fund, the Journal of Applied Crystallography Fund, the Journal of Synchrotron Radiation Fund and the International Tables Fund. STAR/CIF costs, Special Issue costs, journal grants and web input costs are also charged to the Publication and Journals Development account. From 2000, costs associated with the Crystallographic NeXus Project to provide CDROMs (containing crystallographic software and web material) free of charge to developing countries has been charged to this Fund. CHF 146,873 for financial support to young scientists, to enable them to attend scientific meetings sponsored by the Union, and CHF 6,179 for the Visiting Professorship Programme were charged to the Research and Education Fund. 


\section{Auditor's Report to the International Union of Crystallography}

We have audited the financial statements of the International Union of Crystallography for the year ended 31 December 2003 which comprise the income and expenditure account, the balance sheet, the cash flow statement and the related notes 15.1 to 15.15 . These financial statements have been prepared under the accounting policies set out therein.

This report is made solely to the Union's members, as a body, in accordance with Section 11.1 of the Statutes of the Union. Our audit work has been undertaken so that we might state to the Union's members those matters we are required to state to them in an auditor's report and for no other purpose. To the fullest extent permitted by law, we do not accept or assume responsibility to anyone other than the Union and the Union's members as a body, for our audit work, for this report, or for the opinions we have formed.

\section{Respective responsibilities of Executive Committee and Auditors}

As described in the statement of the Executive Committee's responsibilities, the Executive Committee is responsible for the preparation of the financial statements in accordance with applicable law and accounting standards.

Our responsibility is to audit the financial statements in accordance with relevant legal and regulatory requirements and United Kingdom auditing standards.

We report to you our opinion as to whether the financial statements give a true and fair view.

\section{Basis of audit opinion}

We conducted our audit in accordance with United Kingdom auditing standards issued by the Auditing Practices Board. An audit includes examination, on a test basis, of evidence relevant to the amounts and disclosures in the financial statements. It also includes an assessment of the significant estimates and judgements made in the preparation of the financial statements, and of whether the accounting policies are appropriate to the Union's circumstances, consistently applied and adequately disclosed.

We planned and performed our audit so as to obtain all the information and explanations which we considered necessary in order to provide us with sufficient evidence to give reasonable assurance that the financial statements are free from material misstatement, whether caused by fraud or other irregularity or error. In forming our opinion, we also evaluated the overall adequacy of the presentation of information in the financial statements.

\section{Opinion}

In our opinion, the financial statements give a true and fair view of the state of the Union's affairs as at 31 December 2003 and of the result for the year then ended.

\section{Deloitte \& Touche LLP}

Chartered Accountants and Registered Auditors

28 June 2004 


\section{Notes to the Accounts}

The Income and Expenditure Account, the Balance sheet and the Cash Flow statement for the year ended 31 December 2003 are given in Tables 2, 3 and 4.

\subsection{Accounting policies}

(a) Accounting convention

The financial statements are prepared under the historical cost convention, with the exception of investments which are stated at market value, and in accordance with applicable accounting standards. The particular accounting policies adopted are described below.

(b) Rates of exchange

UNESCO rates of exchange as issued by the ICSU Secretariat are used in the preparation of the financial statements.

Transactions denominated in foreign currencies are translated into Swiss Francs at the rates ruling at the dates of the transactions. Monetary assets and liabilities denominated in foreign currencies at the balance sheet date are retranslated at the rates ruling at that date.

Profits and losses arising on trading transactions from the fluctuations in rates of exchange during the year are divided between the fund accounts with credit balances in direct proportion to those balances at the closing balance sheet date. Profits and losses on investments are allocated to the General Fund. All profits and losses arising from exchange rate fluctuations are taken directly to reserves.

\section{(c) Publication costs}

Publication, editorial and administrative expenses of publications are charged in the appropriate income and expenditure account as and when incurred.

\section{(d) Stocks}

Stocks of International Tables are included at the lower of cost and net realizable value. Stocks of all other publications, including back issues of journals, are not valued for accounts purposes as sales are uncertain.

\section{(e) Expenditure on premises}

Expenditure on maintenance of leasehold premises is charged against the appropriate income and expenditure accounts in the year in which it is incurred.

(f) Depreciation

(i) Office equipment is depreciated on the straight line basis at a rate of $20 \%$ per annum.

(ii) Office computer equipment is depreciated on a straight basis at a rate of $331 / 3 \%$ per annum.

(iii) Leasehold property improvements are depreciated over the term of the lease.

(g) Investment income

Notional dividend income re-invested in accumulation investment funds is treated as income when declared and added to the accumulated cost of investments. Other dividends are recognized on an accruals basis.

\section{(h) Investments}

Investments are stated at market value. Changes in market value are taken directly to reserve movements in the General Fund.

(i) Lease costs

Operating lease costs are charged to the income and expenditure account on a straight line basis over the term of the lease. Where reduced rents are payable on property in the earlier years of the lease, the total cost for the period to the first rent review date is spread on a straight line basis, and the appropriate creditor balance is maintained.

(j) Pension costs

The Union operates a defined contribution pension scheme for its employees. The assets of the scheme are held separately from those of the Union. The amount charged to income and expenditure in the year in respect of pensions represents employer's contributions payable in the year. No amounts were due to or from the pension scheme at 31 December 2003 (the same was true in 2002).

\subsection{Rates of exchange}

The assets of the Union are recorded in the financial statements in Swiss Francs but are held in currencies which are considered to be appropriate to the Union's requirements. Transactions in currencies other than Swiss Francs are converted into Swiss Francs at the rate of exchange ruling on the date of the transaction.

The rates of exchange operative at the balance sheet date compared with the Swiss Franc were as follows:

$\begin{array}{lll} & 2003 & 2002 \\ \text { Euros (EUR) } & 0.6477 & 0.6772 \\ \text { Danish Crowns (DKK) } & 4.8231 & 5.0336 \\ \text { Pounds Sterling (GBP) } & 0.4462 & 0.4295 \\ \text { US Dollars (USD) } & 0.7692 & 0.6711\end{array}$

The net assets of the Union at 1 January 2003 (CHF 4,483,185) would have had the value of USD $3,008,665$ or GBP $1,925,528$ if expressed in those currencies.

At 31 December 2003, the net assets (CHF 4,402,667) would have had the value of USD 3,386,531 or GBP $1,964,470$, respectively, being an increase of USD 377,866 or an increase of GBP 38,942 from the previous year.

\subsection{Taxation}

As an association incorporated in Switzerland, the Union is exempt from Swiss Federal and Geneva Cantonal tax. Under the terms of the United Kingdom/Switzerland Double Taxation Agreement dated 8 December 1977, investment income arising within the United Kingdom under present circumstances will not be subject to United Kingdom tax.

Other investment income received from countries with which Switzerland has a Double Taxation Agreement is exempt from tax.

\subsection{Tangible fixed assets}

Table 5 lists the tangible fixed assets.

\subsection{Investments}

Table 6 lists the investments of the IUCr, their disposals and additions and the holding at 31 December 2003.

\subsection{Creditors}

Table 7 lists the creditors, with the amounts falling due within one year for 2002 and 2003.

\subsection{Investment income}

Table 8 lists the income from investments for 2002 and 2003. 


\section{international union of crystallography}

Table 2

Income and Expenditure Account for the year ended 31 December 2003.

\begin{tabular}{|c|c|c|c|c|c|}
\hline & & & & Swiss Francs & \\
\hline & Note & & 2003 & & 2002 \\
\hline Income & & & & & \\
\hline Membership subscriptions & & & 148,215 & & 148,000 \\
\hline Sales & & & & & \\
\hline Journals, back numbers and single issues & & $3,092,668$ & & $3,582,289$ & \\
\hline Books & & 302,843 & $3,395,511$ & 526,067 & $4,108,356$ \\
\hline Investment income & & & & & \\
\hline Income from investments & 15.7 & 49,130 & & 127,878 & \\
\hline Bank interest & 15.8 & 15,802 & & 15,534 & \\
\hline (Loss)/profit on sale of investments & 15.9 & 142,898 & 207,830 & $(48,948)$ & 94,464 \\
\hline Other income & & & & & \\
\hline Royalties and copyright fees & & 8,726 & & 8,437 & \\
\hline Advertising income & & 266,857 & & 146,812 & \\
\hline Donations and grants & & 3,351 & 278,934 & - & 155,249 \\
\hline Total Income & & & $4,030,490$ & & $4,506,069$ \\
\hline Expenditure & & & & & \\
\hline Journals & & & & & \\
\hline Publication costs & & 802,314 & & 838,308 & \\
\hline Editorial expenses & & 159,912 & & 184,384 & \\
\hline Technical editing & & $1,317,349$ & & $1,361,346$ & \\
\hline Subscription administration & & 48,585 & $2,328,160$ & 33,638 & $2,417,676$ \\
\hline Books & & & & & \\
\hline Publication costs & & 39,982 & & 57,374 & \\
\hline Editorial expenses & & 82,688 & & 127,861 & \\
\hline Technical editing & & 26,183 & 148,853 & 176,963 & 362,198 \\
\hline Newsletter & & & & & \\
\hline Publication costs & & 182,767 & & 123,872 & \\
\hline Editorial expenses & & 76,473 & 259,240 & 85,851 & 209,724 \\
\hline $\begin{array}{l}\text { President's Fund Grants } \\
\text { and Young Scientists' support }\end{array}$ & & & 152,836 & & 131,874 \\
\hline General Assembly costs & & & (924) & & 57,155 \\
\hline Ewald Prize & & & - & & 49,005 \\
\hline Committee meetings and expenses & & & 65,886 & & 104,458 \\
\hline Publications and journals development & & & & & \\
\hline General & & 455,620 & & 467,958 & \\
\hline Electronic Publishing Committee/Section & & & & & \\
\hline Editors meeting expenses & & 2,576 & & 1,458 & \\
\hline STAR/CIF & & 2,688 & & 621 & \\
\hline Promotions Officer & & 130,785 & 591,669 & 152,174 & 622,211 \\
\hline Subscriptions paid & & & 9,800 & & 9,971 \\
\hline Visiting Professorship Programme & & & 6,179 & & 8,570 \\
\hline Administration expenses: & & & & & \\
\hline General Secretary and Treasurer: & & & & & \\
\hline Honorarium to Treasurer & & 10,471 & & 12,192 & \\
\hline Audit and accountancy charges & & 60,919 & & 69,828 & \\
\hline Legal and professional fees & & 8,591 & & 16,586 & \\
\hline Travelling expenses & & 9,320 & & 6,290 & \\
\hline Bank charges & & 1,437 & 90,738 & 2,772 & 107,668 \\
\hline Executive Secretary's office: & & & & & \\
\hline Salaries and expenses & & 344,760 & & 351,559 & \\
\hline $\begin{array}{l}\text { Travel expenses of IUCr Representatives on } \\
\text { other bodies }\end{array}$ & & 4.322 & & 3,379 & \\
\hline Commission expenses & & 8,957 & & - & \\
\hline Sponsorship of meetings & & 16,426 & & 46,764 & \\
\hline President's secretary & & 9,542 & & 4,135 & \\
\hline IUCr/FIZ agreement & & $(13,609)$ & 370,398 & $(14,874)$ & 390,963 \\
\hline Depreciation & & & 70,526 & & 75,127 \\
\hline Total Expenditure & & & $4,093,361$ & & $4,546,600$ \\
\hline
\end{tabular}




\section{international union of crystallography}

Table 2 (continued)

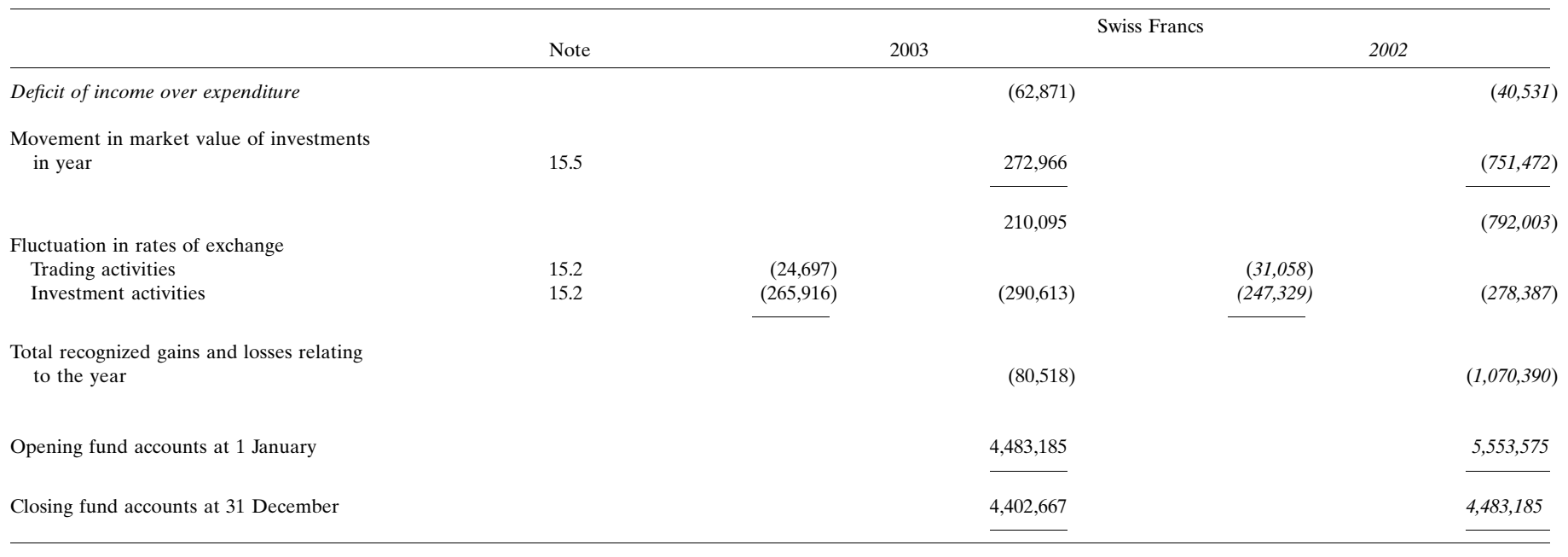

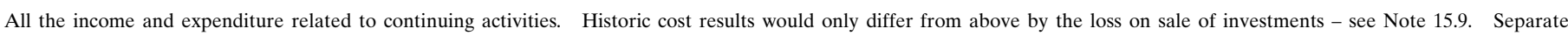
Statements of Total Recognized Gains and Losses and Reconciliation of Movements in Fund Account are not given, as the information is incorporated in the above.

Table 3

Balance sheet as at 31 December 2003.

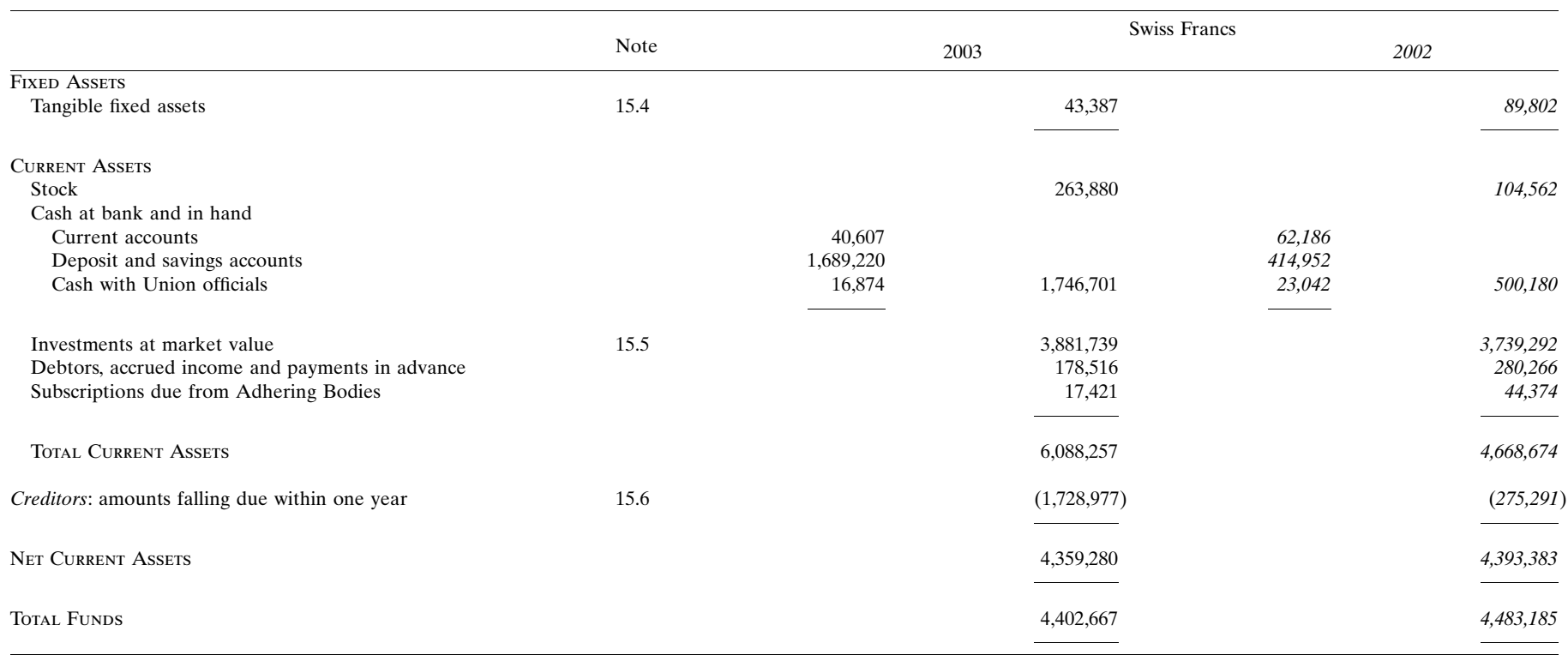

\subsection{Bank interest}

Table 9 lists the bank interest for 2002 and 2003.

\subsection{Loss/profit on disposal/redemption of investments}

Table 10 lists the loss or profit on disposal/redemption of investments for 2002 and 2003.

\subsection{Information regarding employees}

Staff costs during the years 2002 and 2003 are given in Table 11.

\subsection{Operating lease commitments}

At 31 December 2003, the Union was committed to making the payments listed in Table 12 during the next year in respect of operating leases.

\subsection{Sponsorship commitments}

At 31 December 2003, the Union had authorized, but not contracted for, sponsorship grants of CHF 42,900 (2002: CHF 81,950).

15.13. Exchange rate fluctuations attributable to operating activities

Table 13 lists exchange rate fluctuations attributable to operating activities for 2002 and 2003.

\subsection{Analysis of changes in cash during the year}

Table 14 is an analysis of cash changes during 2002 and 2003.

\subsection{Analysis of balances of cash as shown in the balance sheet}

Table 15 is an analysis of cash balances as shown in the balance sheet. 


\section{international union of crystallography}

Table 4

Cash Flow statement for the year ended 31 December 2003.

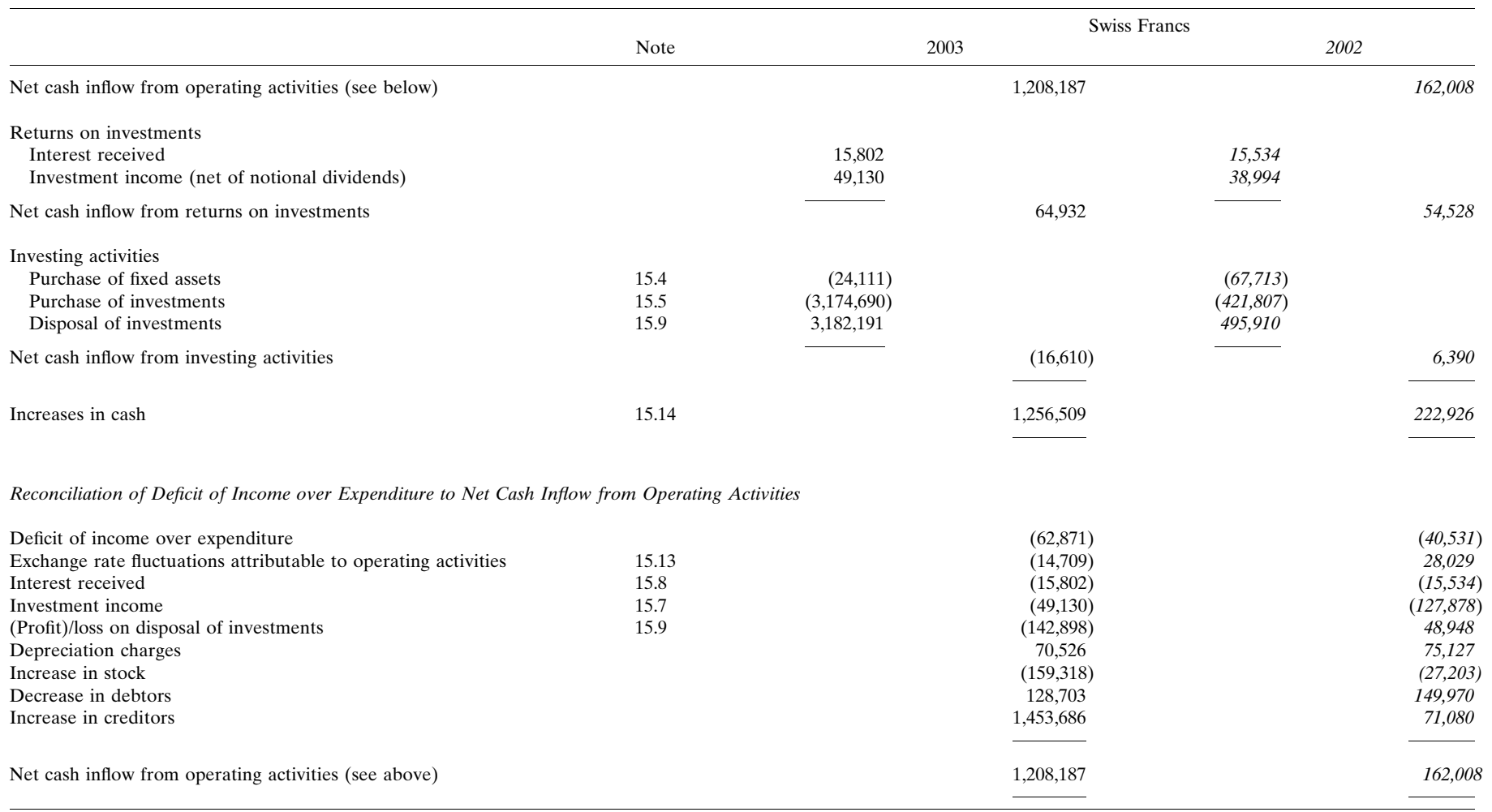

Table 5

Tangible fixed assets.

\begin{tabular}{|c|c|c|c|c|}
\hline & $\begin{array}{l}\text { Leasehold property } \\
\text { improvements } \\
\text { CHF }\end{array}$ & $\begin{array}{c}\text { Office } \\
\text { equipment } \\
\text { CHF }\end{array}$ & $\begin{array}{l}\text { Computer } \\
\text { equipment } \\
\text { CHF }\end{array}$ & $\begin{array}{l}\text { Total } \\
\text { CHF }\end{array}$ \\
\hline \multicolumn{5}{|l|}{ Cost } \\
\hline \multicolumn{5}{|l|}{ As at } \\
\hline 1 January 2003 & 102,987 & 91,893 & 352,396 & 547,276 \\
\hline Additions & - & 805 & 23,306 & 24,111 \\
\hline \multicolumn{5}{|l|}{ As at } \\
\hline 31 December 2003 & 102,987 & 92,698 & 375,702 & 571,387 \\
\hline \multicolumn{5}{|l|}{ Accumulated depreciation } \\
\hline \multicolumn{5}{|l|}{ As at } \\
\hline 1 January 2003 & 74,431 & 78,937 & 304,106 & 457,474 \\
\hline Charge for the year & 10,299 & 4,432 & 55,795 & 70,526 \\
\hline \multicolumn{5}{|l|}{ As at } \\
\hline 31 December 2003 & 84,730 & 83,369 & 359,901 & 528,000 \\
\hline \multicolumn{5}{|l|}{ Net book value } \\
\hline 31 December 2003 & 18,257 & 9,329 & 15,801 & 43,387 \\
\hline 31 December 2002 & 28,556 & 12,956 & 48,290 & 89,802 \\
\hline
\end{tabular}

Tables 16-27 give the accounts for the year ended 31 December 2003 for the various fund accounts. 
international union of crystallography

Table 6

Investments.

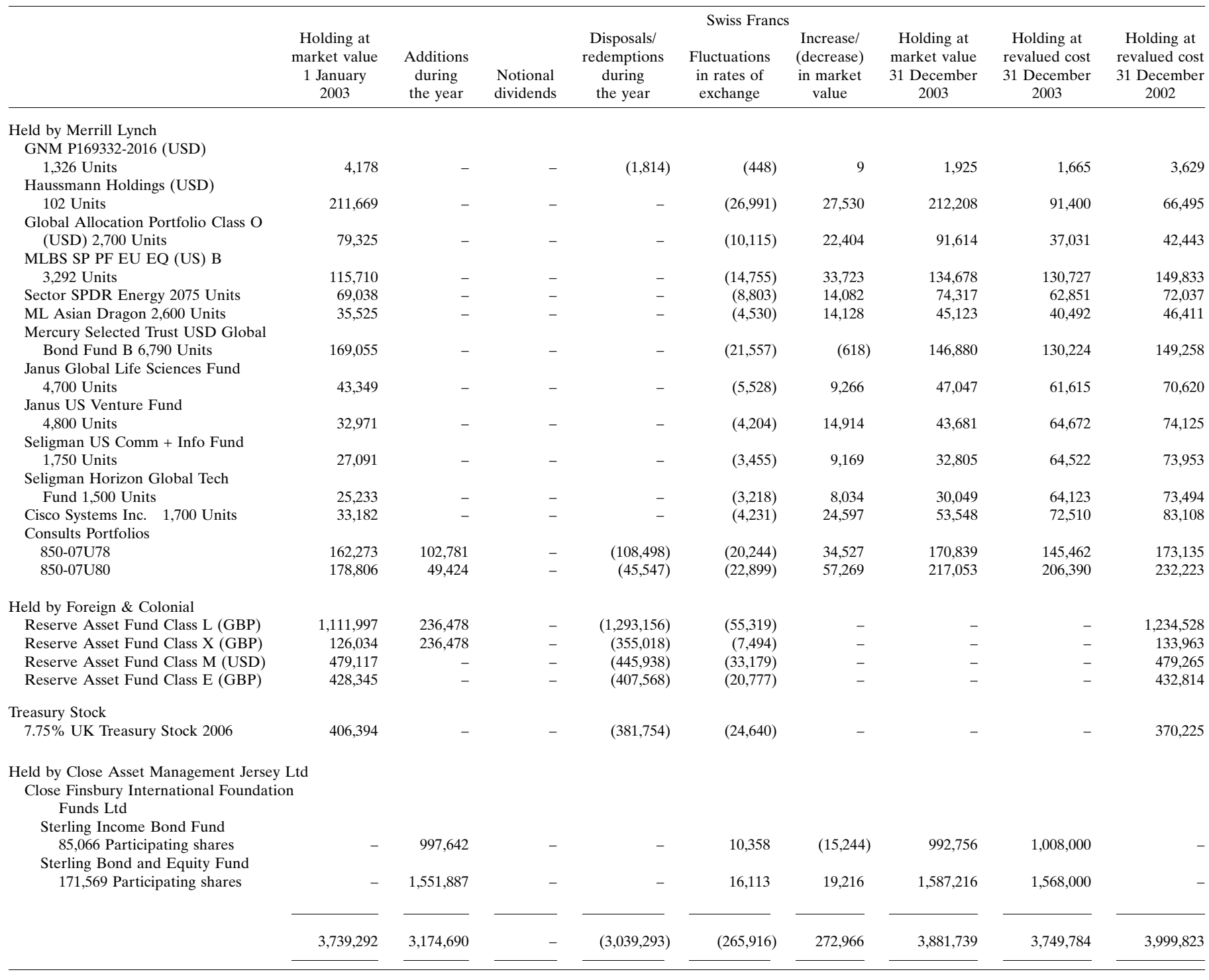




\section{international union of crystallography}

Table 7

Creditors: amounts falling due within one year.

\begin{tabular}{lcc}
\hline & \multicolumn{2}{c}{ Swiss Francs } \\
& 2003 & 2002 \\
\hline Creditors and accruals & $1,677,010$ & 227,808 \\
Payroll creditor including tax and social security & 51,967 & 47,483 \\
& $-1,728,977$ & \\
& & 275,291 \\
\hline
\end{tabular}

Table 8

Investment income.

\begin{tabular}{|c|c|c|}
\hline & & \\
\hline & 2003 & 2002 \\
\hline GNM P169332 - 2016 & 244 & 501 \\
\hline Haussmann Holdings & 288 & 304 \\
\hline Foreign and Colonial - Reserve Asset Fund & & \\
\hline Class $\mathrm{L} \dagger$ & - & 44,628 \\
\hline Foreign and Colonial - Reserve Asset Fund & & \\
\hline Class $\mathrm{X}^{\dagger}$ & - & 5,321 \\
\hline Foreign and Colonial - Reserve Asset Fund & & \\
\hline Class $\mathrm{M}_{\dagger}^{\dagger}$ & - & 9,381 \\
\hline Foreign and Colonial - Reserve Asset Fund & & \\
\hline Class $\mathrm{E} \dagger$ & - & $\begin{array}{l}29,553 \\
27,493\end{array}$ \\
\hline UK Treasury $7.75 \% 22.9 .2006$ & 25,758 & $\begin{array}{r}27,493 \\
1,142\end{array}$ \\
\hline Sector SPDR Strategy & 1,248 & $\begin{array}{r}1,142 \\
143\end{array}$ \\
\hline Pharmaceutical & 11 & 143 \\
\hline Close Finsbury International Ltd Sterling Income Bond & 14,300 & \\
\hline Consults Portfolios & & \\
\hline 850-07U78 & 3,290 & 3,817 \\
\hline 850-07A96 & - & 1,125 \\
\hline 850-07U80 & 3,991 & 3,651 \\
\hline 850-07U81 & - & 819 \\
\hline & 49,130 & 127,878 \\
\hline Allocated to: & & \\
\hline President's Fund & 1,717 & 2,215 \\
\hline Publication and Journals Development Fund & 16,055 & 28,869 \\
\hline Research and Education Fund & 21,433 & 50,361 \\
\hline Ewald Fund & 11,452 & 26,096 \\
\hline Balance left in General Fund & $(1,527)$ & 20,337 \\
\hline & 49,130 & 127,878 \\
\hline
\end{tabular}

$\dagger$ These funds were liquidated during the year and as a result it has not been possible to ascertain the income in price at the date of disposal. Accordingly, no amounts have been allocated to income, all sales proceeds being reported within profit/(loss) on disposal/ redemption of investments.

Table 9

Bank interest.

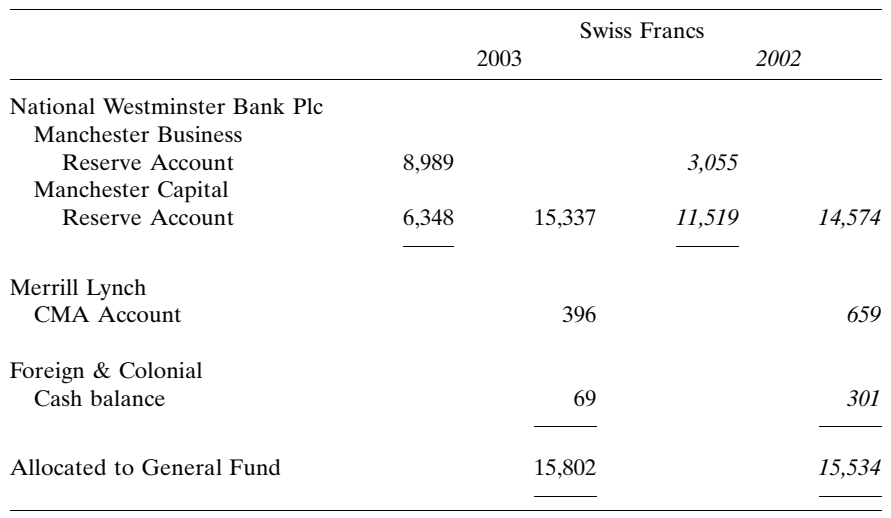

Table 10

Profit/(loss) on disposal/redemption of investments.

\begin{tabular}{lcc}
\hline & 2003 & Swiss Francs \\
\hline Proceeds & $3,182,191$ & 2002 \\
Book value & $\underline{3,039,293}$ & 495,910 \\
Profit/(loss) allocated to General Fund & $\underline{142,898}$ & $\underline{4}$ \\
\hline
\end{tabular}

Book value represents market value at 1 January 2003 or cost if acquired after that date. The profit on disposal based on historic cost was CHF 44,149 (2002: loss of CHF 116,449). Therefore historic cost results would be as follows:

\begin{tabular}{lcc}
\hline & 2003 & Swiss Francs \\
\hline Deficit of income over expenditure & $\underline{(161,620)}$ & $\underline{(108,032)}$ \\
\hline
\end{tabular}

Table 11

Information regarding employees.

\begin{tabular}{|c|c|c|}
\hline & 2003 & 2002 \\
\hline \multirow{2}{*}{$\begin{array}{l}\text { Average number of persons employed } \\
\text { during the year }\end{array}$} & 23 & 23 \\
\hline & \multicolumn{2}{|c|}{ Pounds Sterling } \\
\hline \multicolumn{3}{|l|}{$\begin{array}{l}\text { Staff costs incurred during the year in } \\
\text { respect of these employees: }\end{array}$} \\
\hline Salaries & 722,523 & 677,327 \\
\hline Social security & 77,145 & 56,677 \\
\hline Pension & 122,813 & 118,177 \\
\hline \multirow[t]{3}{*}{ Total staff costs } & 922,481 & 852,181 \\
\hline & \multicolumn{2}{|c|}{ Swiss Francs } \\
\hline & 2003 & 2002 \\
\hline Total staff costs & $2,033,481$ & $1,998,191$ \\
\hline
\end{tabular}

Table 12

Operating lease commitments.

\begin{tabular}{lrrrrr}
\hline & $\begin{array}{c}\text { Land and } \\
\text { Buildings } \\
2003\end{array}$ & \multicolumn{2}{c}{ Swiss Francs } \\
& Other & $\begin{array}{c}\text { Land and } \\
\text { Buildings 2002 }\end{array}$ & $\begin{array}{l}\text { Other } \\
2002\end{array}$ \\
\hline $\begin{array}{l}\text { Leases which expire: } \\
\text { within one year }\end{array}$ & - & 6,185 & - & 41,427 \\
$\begin{array}{l}\text { within one to two years } \\
\text { within two to five years } \\
\text { after five years }\end{array}$ & $-58,266$ & - & - & 6,431 \\
& 25,772 & - & 60,580 & - \\
& & & - & 26,795 & - \\
\hline
\end{tabular}


Table 13

Exchange rate fluctuations attributable to operating activities.

\begin{tabular}{lcc}
\hline & 2003 & Swiss Francs \\
& & 2002 \\
\hline $\begin{array}{l}\text { Total fluctuations in exchange rates dealt } \\
\text { with in fund accounts }\end{array}$ & $(290,613)$ & \\
$\begin{array}{l}\text { Adjustments for exchange differences } \\
\text { attributable to: }\end{array}$ & & \\
$\quad$ Investments (Note 15.5) & $278,387)$ \\
$\quad$ Cash and bank balances & $9,95,916$ & 247,329 \\
& $-(14,709)$ & \\
& & \\
& & $289,087)$ \\
\hline
\end{tabular}

Table 14

Analysis of changes in cash during the year.

\begin{tabular}{|c|c|c|c|c|}
\hline & \multicolumn{4}{|c|}{ Swiss Francs } \\
\hline & \multicolumn{2}{|c|}{2003} & \multicolumn{2}{|c|}{2002} \\
\hline Balance at 1 January 2003 & & 500,180 & & 336,341 \\
\hline Net cash inflow & $1,256,509$ & & 222,926 & \\
\hline $\begin{array}{l}\text { Fluctuations in rates } \\
\text { of exchange on cash } \\
\text { and bank balances }\end{array}$ & $(9,988)$ & $1,246,521$ & $(59,087)$ & 163,839 \\
\hline $\begin{array}{l}\text { Balance at } \\
\quad 31 \text { December } 2003\end{array}$ & & $1,746,701$ & & 500,180 \\
\hline
\end{tabular}

Table 15

Analysis of cash balances as shown in the Balance sheet.

\begin{tabular}{lcccc}
\hline & \multicolumn{2}{c}{ Swiss Francs } \\
& 2003 & 2002 & Change & Change \\
& & 2003 & 2002 \\
\hline Cash at bank and in hand & $1,746,701$ & 500,180 & $1,246,521$ & 163,839 \\
\hline
\end{tabular}

Table 16

Fund Accounts as at 31 December 2003

\begin{tabular}{|c|c|c|c|c|c|c|c|}
\hline & $\begin{array}{c}\text { As at } \\
\text { 1 January } 2003\end{array}$ & $\begin{array}{l}\text { Transfers } \\
\text { between } \\
\text { funds }\end{array}$ & $\begin{array}{l}\text { (Deficit)/ } \\
\text { excess of } \\
\text { income over } \\
\text { expenditure } \\
\text { for the } \\
\text { year }\end{array}$ & $\begin{array}{l}\text { Swiss Francs } \\
\text { Increase in } \\
\text { market } \\
\text { value of } \\
\text { investments }\end{array}$ & \multicolumn{2}{|c|}{$\begin{array}{l}\text { Fluctuations in exchange } \\
\text { rates (Note 15.2) }\end{array}$} & $\begin{array}{l}\text { Balance } \\
\text { at } 31 \text { December } \\
2003\end{array}$ \\
\hline \multicolumn{8}{|l|}{ Fund Accounts } \\
\hline General Fund & 846,085 & - & $(105,661)$ & 272,966 & $(5,333)$ & $(265,916)$ & 742,141 \\
\hline President's Fund & 68,676 & 25,000 & 1,717 & - & $(502)$ & - & 94,891 \\
\hline International Tables & $(24,310)$ & - & 80,060 & - & (293) & - & 55,457 \\
\hline Book Fund & 25,274 & 20,000 & $(27,988)$ & - & (91) & - & 17,195 \\
\hline \multicolumn{8}{|l|}{ Publications and Journals } \\
\hline Development Fund & 774,936 & 250,000 & $(116,691)$ & - & $(4,779)$ & - & 903,466 \\
\hline Research and Education Fund & $1,013,061$ & 140,000 & $(134,294)$ & - & $(5,361)$ & - & $1,013,406$ \\
\hline Ewald Fund & 458,029 & 25,000 & 11,515 & - & $(2,602)$ & - & 491,942 \\
\hline Newsletter Fund & 109,747 & 45,000 & $(29,165)$ & - & $(661)$ & - & 124,921 \\
\hline Journal of Synchrotron Radiation & 125,816 & 30,000 & $(40,179)$ & - & (609) & - & 115,028 \\
\hline
\end{tabular}




\section{international union of crystallography}

Table 17

General Fund Account for the year ended 31 December 2003.

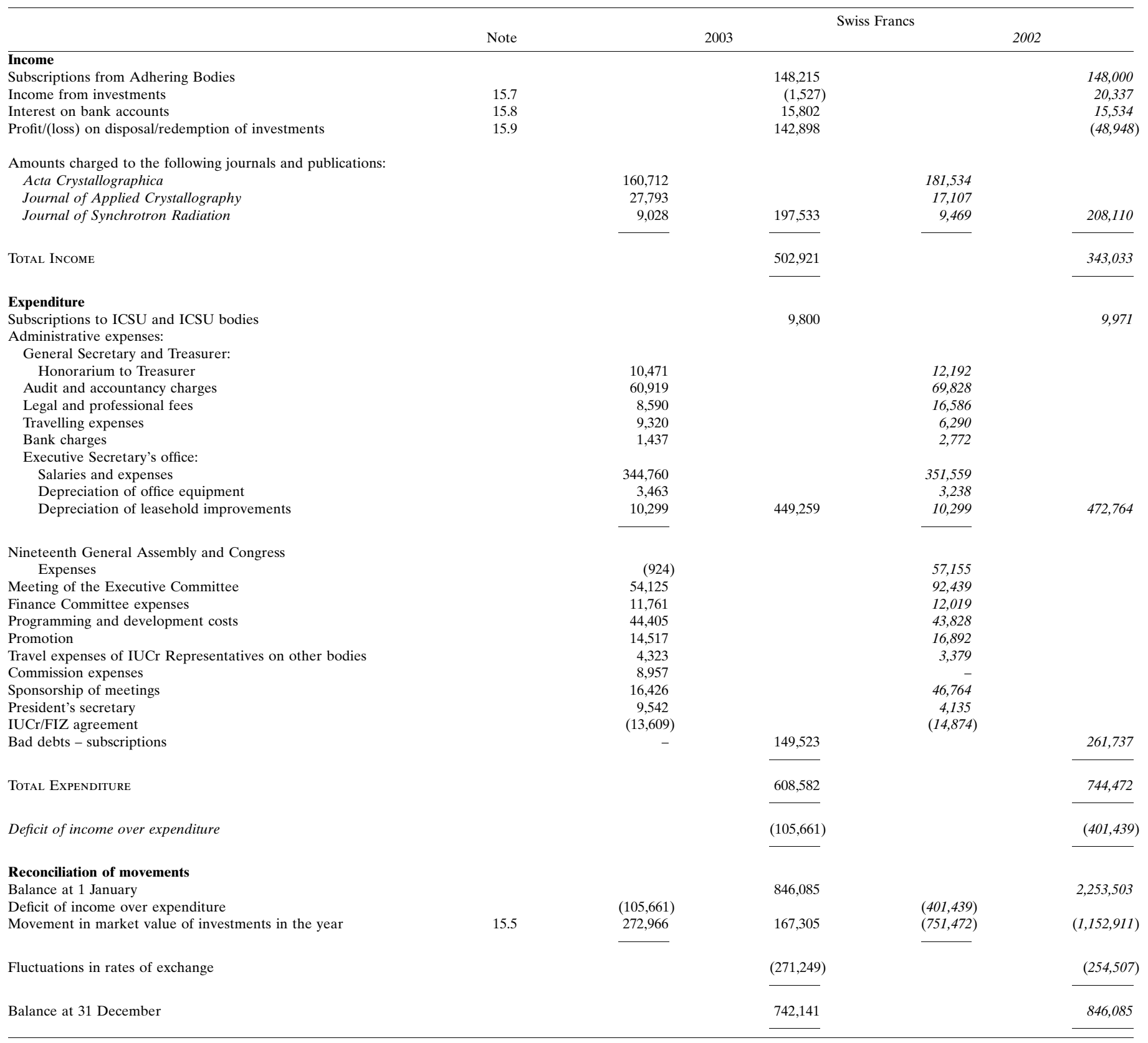


international union of crystallography

Table 18

Acta Crystallographica Account for the year ended 31 December 2003.

Note

Swiss Francs

2003

2002

\section{Income}

Subscriptions to Volume 59 (2002 Volume 58) and sale of back numbers and single copies

Distribution costs charged to subscribers

Royalties and copyright fees

Special Issue income

Pay per view and secondary services (net)

$2,393,390$

94,201

17,827

22,637

9,634

$2,537,689$

172,494

Less Publisher's commission on sales

Income from advertisements (net)

Recharge for Special Issue

TOTAL INCOME

Expenditure

Publication expenses:

Production Volume 59 (2002 Volume 58)

Distribution costs

Net profit on reprints

Special Issue costs

Editorial expenses:

Editorial honoraria

Secretarial assistance

Postage, travel and sundries

Technical editing:

Salaries and expenses

Computer expenses

Subscription administration

Promotion

Depreciation of office equipment

Programming and development costs

Administration expenses recharged from General Fund

TOTAL EXPENDITURE

Surplus of income over expenditure

Reconciliation of movements

Balance at 1 January

Transfers to other funds

Book Fund

Publications and Journals Development Fund

Research and Education Fund

Newsletter Fund

Journal of Synchrotron Radiation

President's Fund

Surplus of income over expenditure

Fluctuations in rates of exchange

Balance at 31 December

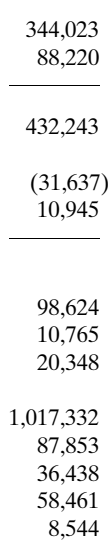

98,624

10,765

017,332

87,853

36,438
58,461

8,544

$\longrightarrow$

$2,365,195$
16,565

$(11,692)$

$2,370,068$

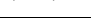

\begin{tabular}{rr} 
& 431,187 \\
& 86,030 \\
\cline { 2 - 2 } & \\
& 517,217 \\
& \\
& \\
& 24,862 \\
& 44,156 \\
& \\
& \\
& 120,495 \\
& 8,046 \\
& 21,727 \\
& 981,341 \\
& 98,051 \\
& 25,228 \\
& 68,022 \\
$1,338,365$ & 13,370
\end{tabular}

259,763

160,712

$2,170,391$

199,677

758,019

$(20,000)$

$(250,000)$

$(140,000)$

$(30,000)$

$(25,000)$

\begin{tabular}{rr} 
& $(120,000)$ \\
& $(270,000)$ \\
& $(130,000)$ \\
& $(25,000)$ \\
$(465,000)$ & $(50,000)$ \\
& $(30,000)$ \\
\hline
\end{tabular}

431,187

86,030

517,217

44,156

20,495

8,046
21,727

81,341

68,022

13,370
2,805,375

8,134

$(1,615)$

2,811,894

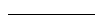

$(24,862)$

536,511

1,336,280

180,133

181,534

$2,234,458$

577,436

810,560

199,677

$(2,593)$

490,103
$(625,000)$

577,436

758,019 


\section{international union of crystallography}

Table 19

Journal of Applied Crystallography Account for the year ended 31 December 2003.

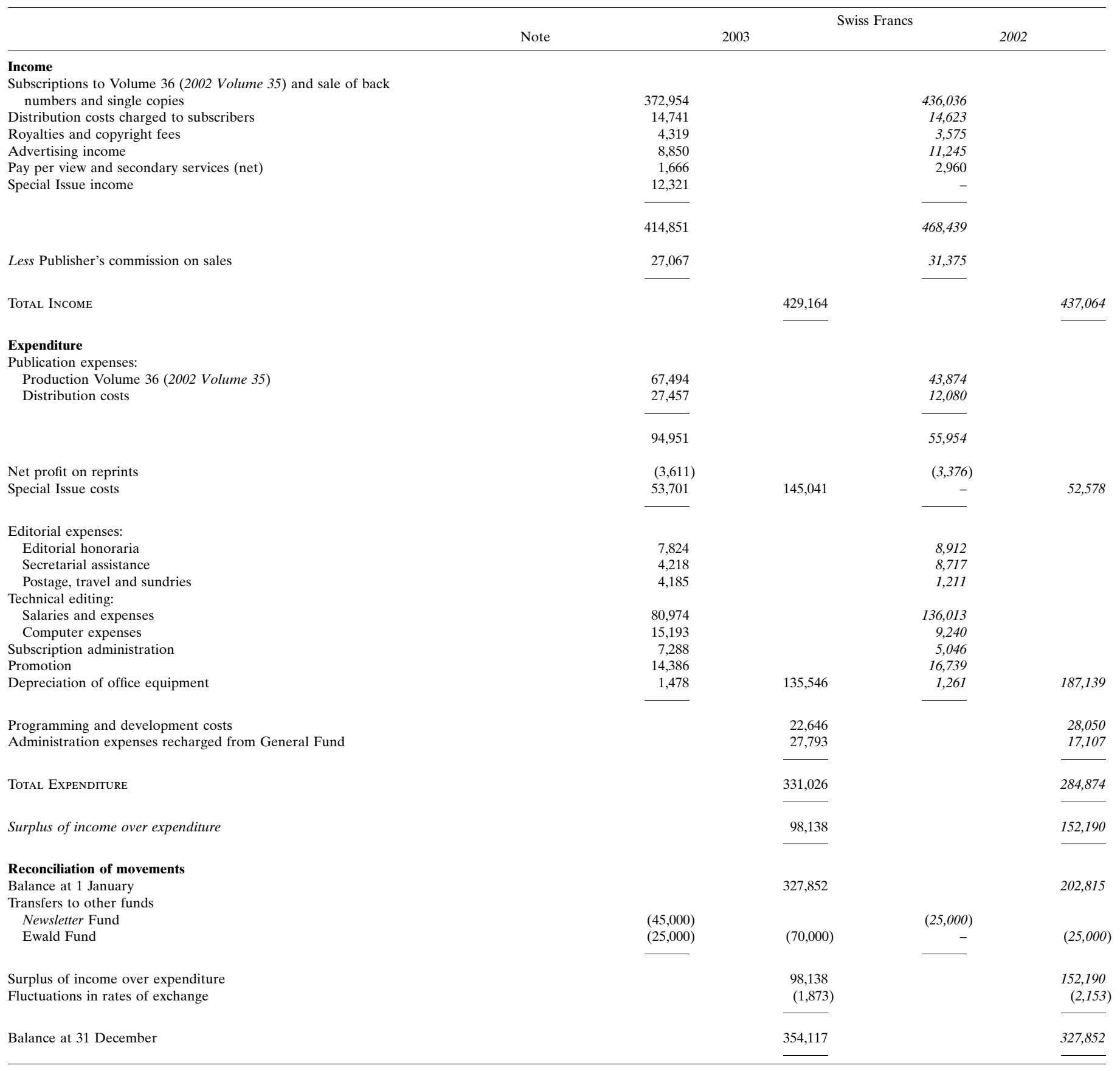


international union of crystallography

Table 20

Journal of Synchrotron Radiation Account for the year ended 31 December 2003.

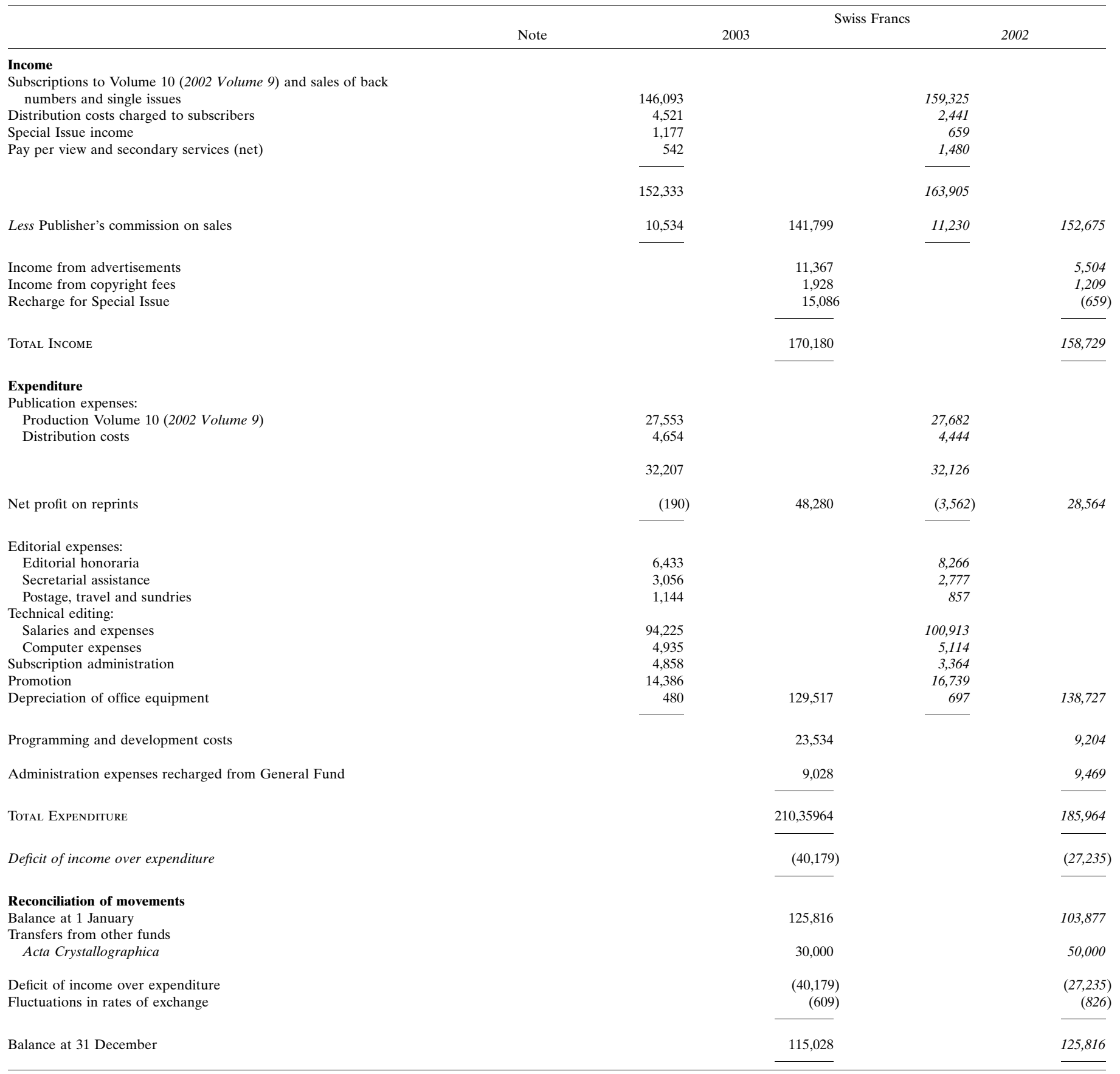




\section{international union of crystallography}

Table 21

President's Fund Account for the year ended 31 December 2003.

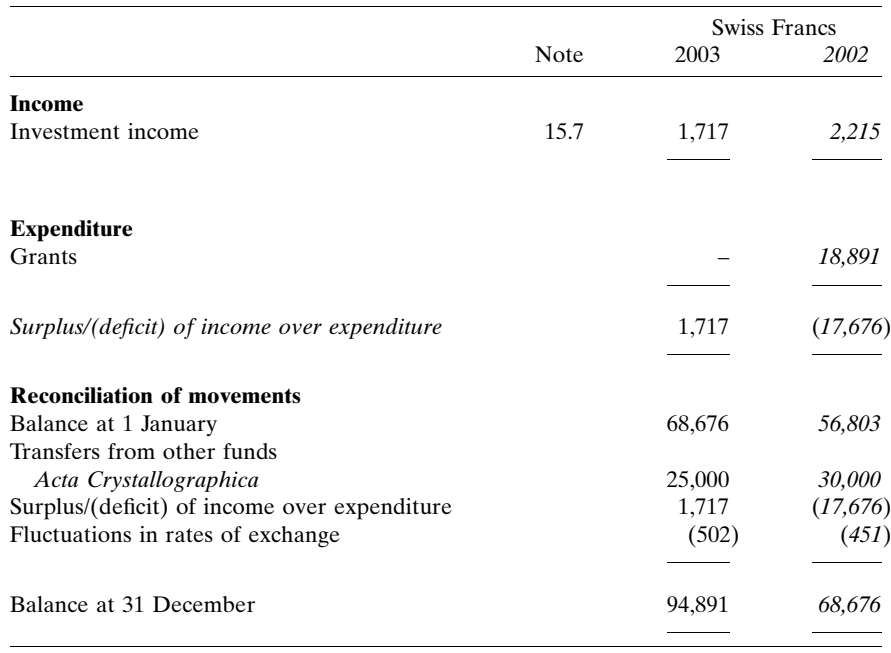

Table 23

Book Fund Account for the year ended 31 December 2003.

\begin{tabular}{|c|c|c|c|}
\hline & \multirow[b]{2}{*}{ Note } & \multicolumn{2}{|c|}{ Swiss Francs } \\
\hline & & 2003 & 2002 \\
\hline \multicolumn{4}{|l|}{ Income } \\
\hline \multicolumn{4}{|l|}{ Sales of copies, net of Publisher's commission on sales } \\
\hline Historical Atlas of Crystallography & & 2 & 86 \\
\hline World Directory of Crystallographers and mailing list & & 4,030 & 1 \\
\hline Escher Kaleidozyklen & & 176 & 45 \\
\hline Structure Reports & & 964 & 70 \\
\hline \multicolumn{4}{|l|}{ Royalties } \\
\hline IUCr/OUP Book Series & & 2,479 & 3,653 \\
\hline Total Income & & 7,651 & 3,855 \\
\hline \multicolumn{4}{|l|}{ Expenditure } \\
\hline \multicolumn{4}{|l|}{ Publication expenses } \\
\hline World Directory of Crystallographers & & 1,584 & 1,824 \\
\hline Programming and development & & 19,538 & 48,211 \\
\hline Promotion & & 14,517 & 16,891 \\
\hline TOtAl EXPENDITURE & & 35,639 & 66,926 \\
\hline Deficit of income over expenditure & & $(27,988)$ & $(63,071)$ \\
\hline \multicolumn{4}{|l|}{ Reconciliation of movements } \\
\hline Balance at 1 January & & 25,274 & $(31,489)$ \\
\hline \multicolumn{4}{|l|}{ Transfers from other funds } \\
\hline Acta Crystallographica & & 20,000 & 120,000 \\
\hline Deficit of income over expenditure & & $(27,988)$ & $(63,071$ \\
\hline Fluctuations in rates of exchange & & (91) & (166) \\
\hline Balance at 31 December & & 17,195 & 25,274 \\
\hline
\end{tabular}

Table 22

International Tables Account for the year ended 31 December 2003.

\begin{tabular}{|c|c|c|c|c|}
\hline & \multicolumn{4}{|c|}{ Swiss Francs } \\
\hline & \multicolumn{2}{|c|}{2003} & \multicolumn{2}{|c|}{2002} \\
\hline \multicolumn{5}{|l|}{ Income } \\
\hline \multicolumn{5}{|l|}{ Sales of copies } \\
\hline Volume A & 70,678 & & 259,939 & \\
\hline Teaching Edition of Volume A & 8,417 & & 16,079 & \\
\hline Volume B & 27,481 & & 43,539 & \\
\hline Volume C & 25,029 & & 39,735 & \\
\hline Volume D & 50,644 & & - & \\
\hline Volume E & 55,493 & & 6,561 & \\
\hline \multirow[t]{2}{*}{ Volume F } & 60,893 & & 114,311 & \\
\hline & 298,635 & & 480,164 & \\
\hline Less Publisher's commission on sales & 77,304 & & 124,449 & \\
\hline Total Income & & 221,331 & & 355,715 \\
\hline \multicolumn{5}{|l|}{ Expenditure } \\
\hline \multicolumn{5}{|l|}{ Publication expenses: } \\
\hline Production Volume A & 9,056 & & 26,386 & \\
\hline Production Volume B & 3,291 & & 5,096 & \\
\hline Production Volume C & 4,235 & & 4,948 & \\
\hline Production Volume D & 7,974 & & - & \\
\hline Production Volume E & 4,253 & & 5,645 & \\
\hline Production Volume F & 6,589 & & 13,209 & \\
\hline \multicolumn{5}{|l|}{ Production Teaching } \\
\hline Edition of Volume A & 3,000 & 38,398 & 266 & 55,550 \\
\hline \multicolumn{5}{|l|}{ Editorial expenses: } \\
\hline Editorial honoraria & 7,500 & & 7,009 & \\
\hline Secretarial assistance and postage & 5,384 & & 3,412 & \\
\hline Technical editing & 26,183 & 39,067 & 176,963 & 187,384 \\
\hline Programming and development & & 49,289 & & 118,335 \\
\hline Promotion & & 14,517 & & 16,891 \\
\hline TOTAL EXPENDITURE & & 141,271 & & 378,160 \\
\hline Surplus/(deficit) of income over expenditure & & 80,060 & & $(22,445)$ \\
\hline \multicolumn{5}{|l|}{ Reconciliation of movements } \\
\hline Balance at 1 January & & $(24,310)$ & & $(2,025)$ \\
\hline Surplus/(deficit) of income over expenditure & & 80,060 & & $(22,445)$ \\
\hline Fluctuations in rates of exchange & & (293) & & 160 \\
\hline Balance at 31 December & & 55,457 & & $(24,310)$ \\
\hline
\end{tabular}


Table 24

Publications and Journals Development Fund Account for the year ended 31 December 2003.

\begin{tabular}{|c|c|c|c|c|c|}
\hline & & & Swiss $\mathrm{F}$ & Francs & \\
\hline & Note & 200 & & 200 & \\
\hline Income & & & & & \\
\hline Investment income & 15.7 & & 16,055 & & 28,869 \\
\hline Expenses & & & & & \\
\hline Computer expenses: & & & & & \\
\hline Programming and development & & 444,039 & & 438,279 & \\
\hline Recharged to other funds & & $(444,039)$ & - & $(438,279)$ & - \\
\hline Electronic Publishing Committee/ & & & & & \\
\hline Section Editors' Meeting & & & 2,576 & & 1,458 \\
\hline Special Issue deficit/(surplus) & & & & & \\
\hline charged/(recredited) from other funds & & & 44,773 & & $(2,274)$ \\
\hline NeXus & & & 3,422 & & 2,141 \\
\hline STAR/CIF & & & 2,688 & & 621 \\
\hline Promotion & & & 130,785 & & 152,174 \\
\hline Promotion recharged to other funds & & & $(130,785)$ & & $(152,174)$ \\
\hline Web input & & & 2,931 & & 2,981 \\
\hline Journal subscription subsidies & & & 30,094 & & 19,088 \\
\hline Digitization project & & & - & & 15,987 \\
\hline Depreciation of computer equipment & & & 46,262 & & 46,262 \\
\hline TOtal Expenditure & & & 132,746 & & 86,264 \\
\hline Deficit of income over expenditure & & & $(116,691)$ & & $(57,395)$ \\
\hline Reconciliation of movements & & & & & \\
\hline Balance at 1 January & & & 774,936 & & 567,419 \\
\hline Transfers from other funds & & & & & \\
\hline Acta Crystallographica & & & 250,000 & & 270,000 \\
\hline Deficit of income over expenditure & & & $(116,691)$ & & $(57,395)$ \\
\hline Fluctuations in rates of exchange & & & $(4,779)$ & & $(5,088)$ \\
\hline Balance at 31 December & & & 903,466 & & 774,936 \\
\hline
\end{tabular}

Table 25

Research and Education Fund Account for the year ended 2003.

\begin{tabular}{|c|c|c|c|c|c|}
\hline & & & Swiss & Francs & \\
\hline & Note & & 2003 & & 02 \\
\hline Income & & & & & \\
\hline Investment income & 15.7 & & 21,433 & & 50,361 \\
\hline Donations & & & 3,288 & & - \\
\hline Total Income & & & 24,721 & & 50,361 \\
\hline Expenditure & & & & & \\
\hline Young Scientists' Support & & 146,873 & & 111,983 & \\
\hline Visiting Professorship Programme & & 6,179 & & 8,570 & \\
\hline Grants & & 5,963 & & - & \\
\hline Total Expenditure & & & 159,015 & & 120,553 \\
\hline Deficit of income over expenditure & & & $(134,294)$ & & $(70,192)$ \\
\hline Reconciliation of movements & & & & & \\
\hline Balance at 1 January & & & $1,013,061$ & & 959,904 \\
\hline Transfers from other funds & & & & & \\
\hline Acta Crystallographica & & & 140,000 & & 130,000 \\
\hline Deficit of income over expenditure & & & $(134,294)$ & & $(70,192)$ \\
\hline Fluctuations in rates of exchange & & & $(5,361)$ & & $(6,651)$ \\
\hline Balance at 31 December & & & $1,013,406$ & & $1,013,061$ \\
\hline
\end{tabular}

Table 26

Ewald Fund Account for the year ended 31 December 2003.

\begin{tabular}{|c|c|c|c|}
\hline & & Swi & \\
\hline & Note & 2003 & 2002 \\
\hline Income & & & \\
\hline Investment income & 15.7 & 11,452 & 26,096 \\
\hline Grants & & 63 & - \\
\hline & & 11,515 & 26,096 \\
\hline Expenditure & & & \\
\hline Prize & & - & 49,005 \\
\hline Surplus/(deficit) of income over expenditure & & 11,515 & $(22,909$ \\
\hline Reconciliation of movements & & & \\
\hline Balance at 1 January & & 458,029 & 483,945 \\
\hline Transfer from other Funds & & & \\
\hline Journal of Applied Crystallography & & 25,000 & \\
\hline Surplus/(deficit) of income over expenditure & & 11,515 & $(22,909$ \\
\hline Fluctuations in rates of exchange & & $(2,602)$ & $(3,007$ \\
\hline Balance at 31 December & & 491,942 & 458,029 \\
\hline
\end{tabular}

Table 27

Newsletter Fund Account for the year ended 2003.

\begin{tabular}{rrrr}
\hline Note & 2003 & Swiss Francs \\
2002 \\
\hline
\end{tabular}

Income

Income from advertisements $230,075 \quad 122,668$

Reimbursement of 19GAC circular

Total Income

230,075

Expenditure

Editorial honoraria

Editorial expenses

Newsletter printing and distribution

Advertising costs

TotAl EXPENDIture

Deficit of income over expenditure

125,253

$\begin{array}{r}125,253 \\ 57,514 \\ \hline\end{array}$

259,240

209,724

$(87,795)$

Reconciliation of movements

Balance at 1 January

Transfers from other funds

Acta Crystallographica

Journal of Applied Crystallography

Deficit of income over expenditure

Current year

Prior year

$(29,165)$

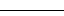

148,263

Fluctuations in rates of exchange

109,747

50,000

$\begin{array}{ll}- & 25,000 \\ 45,000 & 45,000\end{array}$

$\underline{45,000} \quad 45,000 \quad \underline{25,000} \quad 50,000$

Balance at 31 December

$\begin{array}{llll}4,934 & (29,165) & (12,337) & (87,795)\end{array}$

(661) 